\title{
Deposition of microcrystalline silicon prepared by hot-wire chemical-vapor deposition: The influence of the deposition parameters on the material properties and solar cell performance
}

\author{
Stefan Klein, ${ }^{\text {a) }}$ Friedhelm Finger, and Reinhard Carius \\ Institut für Photovoltaik, Forschungszentrum Jülich, 52425 Jülich, Germany \\ Martin Stutzmann \\ Walter Schottky Institut, Technische Universität München, 85748 Garching, Germany
}

(Received 23 December 2004; accepted 23 May 2005; published online 25 July 2005)

\begin{abstract}
Microcrystalline silicon ( $\mu \mathrm{c}-\mathrm{Si}: \mathrm{H})$ of superior quality can be prepared using the hot-wire chemical-vapor deposition method (HWCVD). At a low substrate temperature $\left(T_{S}\right)$ of $185^{\circ} \mathrm{C}$ excellent material properties and solar cell performance were obtained with spin densities of 6 $\times 10^{15} \mathrm{~cm}^{-3}$ and solar cell efficiencies up to $9.4 \%$, respectively. In this study we have systematically investigated the influence of various deposition parameters on the deposition rate and the material properties. For this purpose, thin films and solar cells were prepared at specific substrate and filament temperatures and deposition pressures $\left(p_{D}\right)$, covering the complete range from amorphous to highly crystalline material by adjusting the silane concentration. The influence of these deposition parameters on the chemical reactions at the filament and in the gas phase qualitatively explains the behavior of the structural composition and the formation of defects. In particular, we propose that the deposition rate is determined by the production of reactive species at the filament and a particular atomic-hydrogen-to-silicon ratio is found at the microcrystalline/amorphous transition. The structural, optical, and electronic properties were studied using Raman and infrared spectroscopies, optical-absorption measurements, electron-spin resonance, and dark and photoconductivities. These experiments show that higher $T_{S}$ and $p_{D}$ lead to a deterioration of the material quality, i.e., much higher defect densities, oxygen contaminations, and $\mathrm{SiH}$ absorption at $2100 \mathrm{~cm}^{-1}$. Similar to plasma enhanced chemical-vapor deposition material, $\mu \mathrm{c}-\mathrm{Si}$ :H solar cells prepared with HW $i$ layers show increasing open circuit voltages $\left(V_{\text {oc }}\right)$ with increasing silane concentration and best performance is achieved near the transition to amorphous growth. Such solar cells prepared at low $T_{S}$ exhibit very high $V_{\text {oc }}$ up to $600 \mathrm{mV}$ and fill factors above $70 \%$ with $i$ layers prepared by HWCVD. (C) 2005 American Institute of Physics. [DOI: 10.1063/1.1957128]
\end{abstract}

\section{INTRODUCTION}

Amorphous ( $a$-Si:H) and microcrystalline silicon $(\mu \mathrm{c}-\mathrm{Si}: \mathrm{H})$ are already widely used in microelectronics and solar cell technology. The application in thin-film solar cells promises considerable cost reduction as a result of low material consumption and low process temperatures and the possibility of monolithic series connection of cells. ${ }^{1,2}$ The low consumption of raw material and the low process temperatures during the production result also in low-energy consumption during the production of the solar cells. Among the materials used for thin-film solar cells, amorphous silicon is the most important material in the commercial production of thin-film solar cells. ${ }^{1}$ Microcrystalline silicon combines the advantages of the $a-\mathrm{Si}: \mathrm{H}$ technology and the extended absorption of crystalline silicon at long wavelengths. Thinfilm tandem cell structures comprising amorphous $(a-\mathrm{Si}: \mathrm{H})$ and microcrystalline silicon absorber layers promise significantly higher conversion efficiencies than achieved with $a$-Si:H technology. High efficiencies have been reported by several groups for $a$-Si:H/ $\mu \mathrm{c}-\mathrm{Si}: \mathrm{H}$ tandem cells. ${ }^{3-6}$ However,

\footnotetext{
a) Author to whom correspondence should be addressed; electronic mail: s.klein@fz-juelich.de
}

the low absorption coefficient of $\mu \mathrm{c}-\mathrm{Si}: \mathrm{H}$ requires 1-2- $\mu \mathrm{m}$-thick absorber layers, and therefore high deposition rates, despite the progress in the development of lighttrapping structures. Plasma-enhanced chemical-vapor deposition (PECVD) is up to now the standard technology for the deposition of $a-\mathrm{Si}: \mathrm{H}$ and $\mu \mathrm{c}-\mathrm{Si}: \mathrm{H}$ for various applications and is applied with great success. Thus, single junction conversion efficiencies of approximately $9 \%$, improvements in the deposition rates, and successful upscaling to large area deposition were recently achieved. ${ }^{1,3-8}$ However, in view of the necessity for high deposition rates on large areas, further progress is required. In this context, so-called hot-wire (HW) or catalytic (CAT) chemical-vapor deposition ${ }^{9-11}$ (CVD) has received much attention due to its very high deposition rates for $\mu \mathrm{c}-\mathrm{Si}: \mathrm{H}\left(30 \AA / \mathrm{s}\right.$ and above ${ }^{12,13}$ ) and the potential for upscaling. ${ }^{14,15}$ Furthermore, the absence of ions might simplify the chemistry of the deposition process and the understanding of the $\mu \mathrm{c}-\mathrm{Si}: \mathrm{H}$ growth process could thereby be improved.

For material prepared at high substrate temperatures, high crystalline volume fractions and large grain sizes are obtained but the defect densities are high too, the material is porous and subject to in-diffusion of atmospheric gases, and 
the resulting solar cell efficiencies were low. ${ }^{16}$ In a previous investigation we have identified the substrate temperature as being one of the key factors for controlling the $\mu \mathrm{c}-\mathrm{Si}: \mathrm{H}$ material quality in the HWCVD process. ${ }^{17}$ In particular, it was found that high filament temperatures, used to achieve an effective process gas decomposition and therefore high deposition rates, generally lead to considerable additional substrate heating. It was concluded that at deposition temperatures above $300{ }^{\circ} \mathrm{C}$ the enhanced hydrogen desorption during the growth process results in insufficient grain-boundary passivation. Similar observations were made for material prepared by PECVD, ${ }^{18,19}$ suggesting that the deposition temperature has a very similar influence on the growth of $\mu \mathrm{c}-\mathrm{Si}: \mathrm{H}$ regardless of the deposition technique. Here, we report on the critical issues in HWCVD, particularly the implementation of low substrate temperatures in order to prepare material with high quality. Greatly reduced spin densities, very low oxygen in-diffusion, and solar cell efficiencies being similar to those of devices fabricated using PECVD material evidence the success of this approach. We apply our knowledge about $\mu \mathrm{c}-\mathrm{Si}: \mathrm{H}$ solar cells prepared by PECVD to devices including HWCVD material. ${ }^{19,20}$ In particular, we have shown that, for HWCVD material like for PECVD material, optimum solar cell performance is achieved with $\mu \mathrm{c}-\mathrm{Si}: \mathrm{H}$ absorber layers prepared near the transition to amorphous growth. ${ }^{19,21}$ Recently, we have succeeded in the preparation of $\mu \mathrm{c}-\mathrm{Si}: \mathrm{H}$ solar cells ${ }^{21,22}$ with absorber layers prepared by HWCVD with very high efficiencies. These solar cells, prepared at low substrate temperatures at deposition rates of $1 \AA / \mathrm{s},{ }^{22}$ exhibit exceptionally high open circuit voltages of $\approx 600 \mathrm{mV}$ at high fill factors above $70 \%$.

It is now of major technological interest to increase the deposition rates without sacrificing the material quality. A better understanding of the deposition process, acquired by a systematic investigation of the influence of the deposition parameters, finally helps to increase the deposition rate. A prerequisite for high deposition rates is the effective decomposition of the process gases. In HWCVD this can be accomplished either by high filament temperatures $T_{F}$ or by a large surface area of the filament. The dissociation of silane and hydrogen, commonly used as process gases, can be described by the following equations:

$$
\begin{aligned}
& \mathrm{SiH}_{4} \rightarrow \mathrm{Si}+2 \mathrm{H}_{2}, \\
& \mathrm{H}_{2} \rightarrow 2 \mathrm{H} .
\end{aligned}
$$

The dissociation of silane, and thus the deposition rate, shows a thermally activated behavior and a saturation of the dissociation is observed at high $T_{F}\left(T_{F}>1800-2000{ }^{\circ} \mathrm{C}\right)$, depending on the deposition conditions. ${ }^{23-25}$ For the activation energy $E_{A}^{\mathrm{Si}}$ of the silane dissociation, a large uncertainty persists, values between 96 (Ref. 25) and $600 \mathrm{~kJ} / \mathrm{mol}$ (Ref. 23) are reported. The concentration of dissociated hydrogen was observed to be in thermal equilibrium with the filament and an activation energy $E_{A}^{\mathrm{H}}$ of $239 \mathrm{~kJ} / \mathrm{mol}$ was measured, ${ }^{26}$ in good agreement with the binding energy of the $\mathrm{H}-\mathrm{H}$ bond.

Besides the generation of radicals, the transport of the radicals from the filament to the substrate surface has a crucial impact on the film properties. The reactions on the way
TABLE I. Reaction-rate constants $k$ and reaction enthalpy $\Delta \mathrm{H}$ of important gas phase reactions obtained from PECVD for a gas temperature of $500 \mathrm{~K}$.

\begin{tabular}{crcc}
\hline \hline & $\begin{array}{c}\text { Reaction } \\
\text { enthalpy } \\
\text { Reaction }\end{array}$ & $\begin{array}{c}\text { Rate constant } \\
k\left(\mathrm{~cm}^{3} / \mathrm{mol} \mathrm{s}\right)\end{array}$ & Reference \\
\hline & & & \\
collision limit for $\mathrm{Si}+\mathrm{SiH}_{4}$ & 0 & $1.3 \times 10^{14}$ & 76 \\
$\mathrm{Si}+\mathrm{SiH}_{4} \rightarrow \mathrm{HSiSiH}_{3}^{*}$ & -2.0 & $4 \times 10^{14}$ & 77 \\
$\mathrm{H}+\mathrm{SiH}_{4} \rightarrow \mathrm{SiH}_{3}+\mathrm{H}_{2}$ & -0.54 & $7.2 \times 10^{14} e^{-1250} \mathrm{~K} / \mathrm{T}$ & 70 \\
$\mathrm{H}+\mathrm{SiH}_{3} \rightarrow \mathrm{SiH}_{2}+\mathrm{H}_{2}$ & -1.46 & $5.2 \times 10^{14}$ & 70 \\
$\mathrm{SiH}_{3}+\mathrm{SiH}_{3} \rightarrow \mathrm{H}_{3} \mathrm{SiSiH}_{3}$ & -0.91 & $2.4 \times 10^{14}$ & 70 \\
\hline \hline
\end{tabular}

from the filament to the substrate are influenced by the deposition pressure $p_{D}$ and the distance $d_{S F}$ between the filaments and the substrate. The abstraction reaction of hydrogen [Eq. (3)] and the insertion reaction of Si into silane [Eq. (4)] are assumed to be the most important ${ }^{27-29}$

$$
\begin{aligned}
& \mathrm{H}+\mathrm{SiH}_{4} \rightarrow \mathrm{SiH}_{3}+\mathrm{H}_{2}, \\
& \mathrm{Si}+\mathrm{SiH}_{4} \rightarrow \mathrm{HSiSiH}_{3}^{*} .
\end{aligned}
$$

This can be seen by the comparison of the reaction-rate constants and the collision rate constant, calculated from the atomic cross section, both given in Table I. The reaction rates for these two reactions are of the order of the collision rate for a silicon atom with silane, i.e., the probability for a chemical reaction is close to unity upon a collision with a silane molecule. At very low $p_{D}$ no reactions of the primary radicals $(\mathrm{Si}$ and $\mathrm{H}$ ) take place in the gas phase and $\mathrm{Si}$ atoms reach the substrate. This leads to disordered material due to the high sticking probability of $\mathrm{Si}$ atoms. ${ }^{30}$ At intermediate pressures, when few collisions of $\mathrm{Si}$ and $\mathrm{H}$ according to the reactions [Eqs. (3) and (4)] occur, more favorable radicals are formed. For amorphous silicon, Refs. 24 and 28 have shown that the optimal pressure depends on the filamentsubstrate distance and an optimal value for the product $p_{D} d_{S F}$ was found. At higher pressures, multiple reactions of the radicals occur and higher silanes or $\mathrm{SiH}$ and $\mathrm{SiH}_{2}$ are formed $^{29,31}$ by further abstraction reactions which leads to a porous structure of the material. ${ }^{32}$ The influence of the precursors on the material properties is discussed controversially, especially the role of the di- and trisilanes raises much disagreement. ${ }^{28,32-34}$

The deposition rate of the films is determined by the flux of radicals impinging on the substrate and the reaction probability with the film surface. For low pressures, if the mean free path $\left(\lambda_{\mathrm{mfp}}\right)$ for the silicon atoms is in the order of $d_{S F}$, it was shown that the flux follows a $1 / d^{2}$ dependence, where $d$ is the distance between a point source and a point on the substrate and that the total flux can be obtained from integration along the filaments. ${ }^{10,24}$ Atomic silicon, $\mathrm{SiH}$, and $\mathrm{SiH}_{2}$ have much higher surface reaction rates than $\mathrm{SiH}_{3}$ because the former radicals can directly insert in a $\mathrm{SiH}$ bond of the surface while $\mathrm{SiH}_{3}$ requires a surface dangling bond. Thus, the reactions in the gas phase result in changes of the surface reactivity of the precursors, the abstraction of hydrogen leads to more reactive radicals, the insertion of $\mathrm{Si}$ in silane to less reactive radicals. 
However, the situation for the deposition rate of $\mu \mathrm{c}-\mathrm{Si}: \mathrm{H}$ is much more complicated, since the variation of any deposition parameter also affects the structural composition of the film. For the growth of microcrystalline silicon, the presence of atomic hydrogen is of great importance. The role of hydrogen for the growth of microcrystalline silicon is described qualitatively by a number of models. The growth-zone model describes the formation of $\mu \mathrm{c}-\mathrm{Si}: \mathrm{H}$ silicon by the relaxation of stressed $\mathrm{Si}-\mathrm{Si}$ bonds and chemical annealing through the exothermic reaction of $\mathrm{H}$ and $\mathrm{SiH}_{3} \cdot{ }^{35-37}$ The preferential etching model explains the formation of $\mu \mathrm{c}-\mathrm{Si}: \mathrm{H}$ by the preferred etching of amorphous silicon by atomic hydrogen. ${ }^{38-40}$ The surface diffusion model explains the microcrystalline growth by the hydrogen coverage of the surface and the enhanced diffusion of the precursors. ${ }^{41,42}$

Extensive material analyses were performed in this study. The influence of the substrate temperature on the structural, optical, and electronic properties was studied by a variety of methods. It will be shown that the material quality improves substantially by using low substrate temperatures. However, the low substrate temperatures could be achieved only by using low filament temperatures and small filament surface areas. In order to increase the deposition rates while maintaining a good material quality, the impact of the deposition pressure and the filament temperature on the deposition rates and the material properties is investigated in Sec. III C. Section III D summarizes the properties of $\mu \mathrm{c}-\mathrm{Si}: \mathrm{H}$ solar cells prepared under these optimized conditions at low $T_{S}$. Correlations between the deposition parameters, material properties, and solar cell performance are presented. Finally, the influence of the deposition conditions, and hence the influence of atomic $\mathrm{H}$ and gas-phase reactions, on the growth and the quality of $\mu \mathrm{c}-\mathrm{Si}: \mathrm{H}$ is discussed.

\section{EXPERIMENTAL METHODS}

The material and solar cells investigated in this paper were prepared in a multichamber deposition system, with three PECVD chambers in standard diode-type electrode configuration, one HWCVD chamber, a load-lock, and a central transfer chamber with an additional preheat station. With this setup we are able to individually exchange the intrinsic absorber layer ( $i$ layer) in the solar cells from PECVD- to HWCVD-grown material and compare the performance of the HWCVD $\mu \mathrm{c}-\mathrm{Si}: \mathrm{H}$ with the high standard already achieved for PECVD $\mu \mathrm{c}-\mathrm{Si}: \mathrm{H}$ solar cells. The HW setup can hold several filaments at an adjustable distance between 50 and $100 \mathrm{~mm}$ from the substrate. The substrates are heated by radiation from an electrically heated graphite plate $3 \mathrm{~cm}$ behind the substrate and by radiation from the filaments. The system reaches a base pressure $<1 \times 10^{-6} \mathrm{~Pa}$. All gas lines are equipped with gas purifiers. For the hot wire we used 2-4 coiled tantalum filaments with $0.5 \mathrm{~mm}$ in diameter at a typical distance of $70 \mathrm{~mm}$ from the substrate. The $i$ layers were deposited at filament temperatures $T_{F}$ between 1650 and $1850{ }^{\circ} \mathrm{C}$, measured with a dual-beam pyrometer. The substrate temperature was calibrated with Pt-100 thermoresistors fixed to a glass substrate. ${ }^{17}$

The material was prepared on aluminosilicate glass
(Corning 1737), quartz, and crystalline silicon under identical conditions to those of the solar cells. The sample thickness was determined with a mechanical stylus profiler at three points on the $10 \times 10-\mathrm{cm}^{2}$ substrate (center, edge, and corner). A thickness inhomogeneity of $35 \%$ between the center and corner was found in worst case, typical values are $\pm 10 \%$. Samples for all other measurements were taken from the middle of the substrate. The samples were characterized by Raman and infrared [Fourier transform infrared (FTIR)] spectroscopies, dark- and photoconductivity measurements, photothermal deflection spectroscopy (PDS), and electronspin resonance (ESR). As a measure for the crystallinity of the material we used the ratio $I_{C}^{\mathrm{RS}}$ of the Raman intensity of the crystalline peaks to the combined intensity of the crystalline and amorphous peaks. For that purpose, the spectrum was deconvoluted into three Gaussian peaks at 520 and $500 \mathrm{~cm}^{-1}$ for the crystalline fraction and $480 \mathrm{~cm}^{-1}$ for the amorphous phase, giving $I_{C}^{\mathrm{RS}}=\left(I_{520}+I_{500}\right) /\left(I_{520}+I_{500}+I_{480}\right)$. The IR spectra were measured with a Bruker IFS66V vacuum Fourier transform infrared spectrometer. The hydrogen content was determined from the intensity of the $\mathrm{SiH}$ wagging modes using a calibration constant $A_{640}$ of 1.6 $\times 10^{19} \mathrm{~cm}^{-2}$. ${ }^{43,44}$ The microstructure factor $R$ is defined as the ratio of the intensity of the $\mathrm{SiH}$ stretching mode at $2100 \mathrm{~cm}^{-1}$ to the total intensity of the $\mathrm{SiH}$ stretching modes. For ESR, approximately $2-3-\mu \mathrm{m}$-thick samples were deposited on aluminum foil for the preparation of powder samples. ${ }^{45}$ The conductivity measurements were performed in coplanar configuration in high vacuum after annealing the samples for $30 \mathrm{~min}$ at $170{ }^{\circ} \mathrm{C}$. The photoconductivity was measured with a tungsten lamp where the intensity was calibrated to the intensity of an AM 1.5 spectrum.

The $\mu \mathrm{c}-\mathrm{Si}: \mathrm{H}$ solar cells were deposited in the $p-i-n$ deposition sequence onto a textured glass/ZnO substrate ${ }^{46}$ with $p$ and $n$ layers prepared by PECVD. The active area of each cell was $1 \mathrm{~cm}^{2}$, defined by the geometry of the Ag back reflector. The $J-V$ characteristics were recorded at a temperature of $25^{\circ} \mathrm{C}$ with a class A double source solar simulator providing an AM 1.5 spectrum with an intensity of $100 \mathrm{~mW} / \mathrm{cm}^{2}$.

\section{RESULTS}

\section{A. Calibration of the substrate temperature}

The heat radiation from the filaments has a substantial impact on the substrate temperature $T_{S}$, as indicated in Fig. 1. The filament temperature, number of filaments, and the distance to the substrate as well as the presence of gases and the pressure have a strong influence on the substrate temperature. Without heating the filaments, there is an almost linear relation between the heater temperature $T_{H}$ and $T_{S}$, which is roughly $100{ }^{\circ} \mathrm{C}$ lower than $T_{H}$, with a good temperature homogeneity across the substrate (less than $30^{\circ} \mathrm{C}$ colder towards the edge in the worst case). With the filaments switched on, there is a strong additional substrate heating such that at low $T_{H}$ the substrate temperature is determined by the radiation from the filaments, yielding $T_{S} \approx 190{ }^{\circ} \mathrm{C}$ for three filaments at $T_{F}=1400-1600{ }^{\circ} \mathrm{C}$ and $T_{H}=150{ }^{\circ} \mathrm{C}$ or $T_{S}$ $\approx 280{ }^{\circ} \mathrm{C}$ for four filaments at $T_{F}=1740{ }^{\circ} \mathrm{C}$. The presence of 


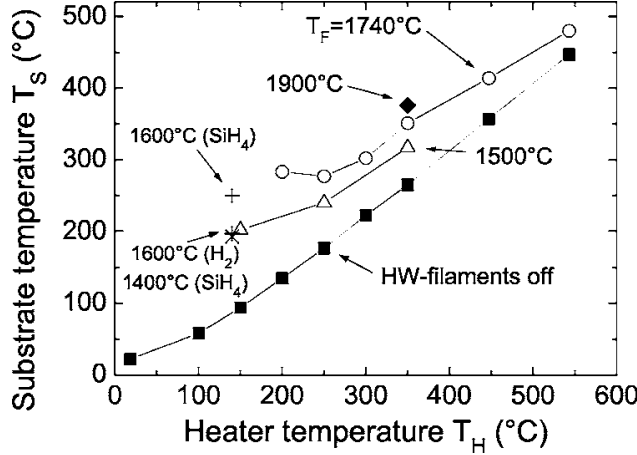

FIG. 1. Substrate temperature $T_{S}$ as a function of the heater temperature $T_{H}$ for different filament temperatures $T_{F}$, three or four filaments, and additional process gases at a pressure of $5 \mathrm{~Pa}$.

deposition gases affects the substrate temperature in two ways: firstly, the heat transport to and from the substrate is enhanced. Secondly, the gas molecules dissociate at the filament and more electric power is necessary to heat the filament to a certain temperature. At a filament temperature of $1600{ }^{\circ} \mathrm{C}$, the presence of $\mathrm{H}_{2}$ at a pressure of $5 \mathrm{~Pa}$ leads to the same $T_{S}$ as $T_{F}=1400{ }^{\circ} \mathrm{C}$ at the presence of $\mathrm{SiH}_{4}$, while $T_{F}$ $=1600{ }^{\circ} \mathrm{C}$ at the presence of $\mathrm{SiH}_{4}$ leads to an approximately $50{ }^{\circ} \mathrm{C}$ higher $T_{S}$ because more power is needed to heat the filament due to the heat transfer by $\mathrm{SiH}_{4}$ or reactions at the surface of the filament.

\section{B. Silane concentration and substrate temperature}

\section{Deposition rates}

Figures 2 and 3 show the deposition rates $r_{d}$ for the material grown from $\mathrm{SiH}_{4} / \mathrm{H}_{2}$ mixtures as a function of the silane concentration (SC), substrate temperature $T_{S}$, and filament temperature $T_{F}$. In Fig. 2 the deposition rates are plotted versus SC for different substrate temperatures and filament configurations. For all conditions, a nearly linear increase of $r_{d}$ with $\mathrm{SC}$ is observed. At $T_{S}=185^{\circ} \mathrm{C}$ and $T_{S}$ $=220^{\circ} \mathrm{C}$, the substrate was solely heated by the radiation from the filaments, i.e., the substrate heater on the backside of the substrate was switched off. At $T_{S}=185{ }^{\circ} \mathrm{C}$ only two filaments were used, which leads to about 50\% lower deposition rates. For the films prepared at higher $T_{S}$, additional

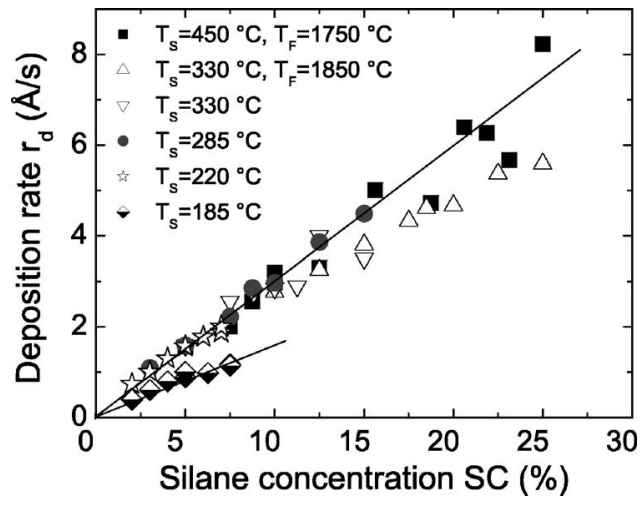

FIG. 2. Deposition rates as a function of the silane concentration SC for different substrate temperatures $T_{S}$ with three filaments at a filament temperature of $T_{F}=1650^{\circ} \mathrm{C}$ if not otherwise noted. Two filaments were used at $T_{S} \approx 185^{\circ} \mathrm{C}$. The deposition pressure was $5 \mathrm{~Pa}$ for all films.

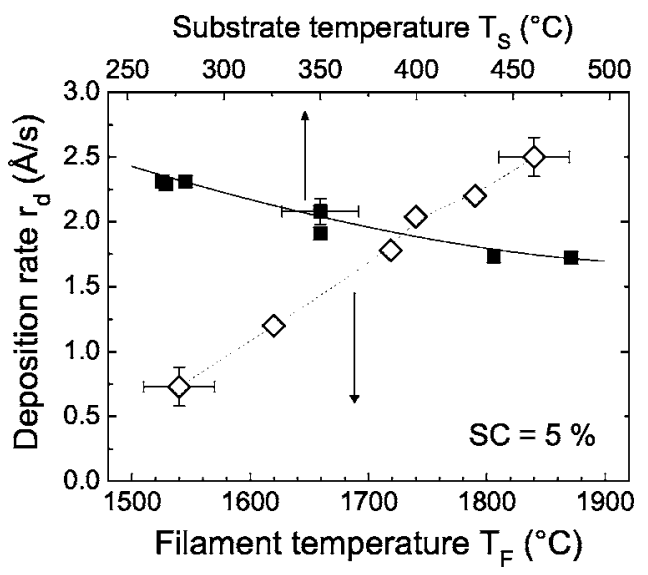

FIG. 3. Deposition rates as a function of the filament temperature $T_{F}\left(\diamond: T_{S} \approx 350{ }^{\circ} \mathrm{C}\right)$ and substrate temperature $T_{S}\left(\boldsymbol{\square}: T_{F}=1650{ }^{\circ} \mathrm{C}\right)$. The silane concentration is $5 \%$.

heat was provided by the substrate heater. Similar deposition rates for fixed SC are observed for $T_{S} \geqslant 220{ }^{\circ} \mathrm{C}$. For the films prepared at higher $T_{F}$, other filament geometries (larger filament-substrate distance, shorter filaments) were used, thus compensating the increase of $r_{d}$ expected for higher $T_{F}$. The influence of the substrate temperature and filament temperature on the deposition rate for fixed SC is depicted in Fig. 3. An increase of $T_{F}$ leads to an increase of the deposition rate which can be attributed to a more efficient gas decomposition at higher filament temperatures. ${ }^{23-25}$ A leastsquare fit to the data gives an activation energy for the deposition rate of $130 \pm 30 \mathrm{~kJ} / \mathrm{mol}$. The substrate temperature shows the opposite effect and has a much weaker influence on $r_{d}$, showing a decrease from $2.3 \AA / \mathrm{s}$ at $T_{S}=270{ }^{\circ} \mathrm{C}$ to $1.8 \AA / \mathrm{s}$ at $T_{S}=450{ }^{\circ} \mathrm{C}$ using three filaments at $T_{F}=1650{ }^{\circ} \mathrm{C}$.

Furthermore, the geometry of the chamber and the filaments has a strong influence on the deposition rate. $r_{d}$ is proportional to the filament surface area and decreases with increasing filament-substrate distance. ${ }^{10,47}$ However, large filament surface areas and small filament-substrate distances $d_{\mathrm{SF}}$ lead to an enhanced heating of the substrate, too. Additionally, small $d_{\mathrm{SF}}$ require small filament-filament spacings to obtain a homogeneous deposition rate and substrate temperature. ${ }^{15,28,48}$ Thus, radiation of the filaments limits the deposition rate at low $T_{S}$.

\section{Raman spectroscopy}

The semiquantitative measure $I_{C}^{\mathrm{RS}}$ for the crystallinity of the material-defined by the Raman intensity ratio of the integrated peak intensity of the crystalline peaks at 520 and $500 \mathrm{~cm}^{-1}$ to the total scattering intensity of the amorphous and crystalline peaks - is shown in Fig. 4 as a function of the silane concentration SC. The spectra were taken with an excitation wavelength of $488 \mathrm{~nm}$ from the film surface side in order to minimize the contributions of the nucleation layer often observed at the substrate/film interface. For all relevant temperatures, $T_{F}$ and $T_{S}, I_{C}^{\mathrm{RS}}$ decreases monotonously with increasing $\mathrm{SC}$. Depending on $T_{S}$, the transition from amorphous to microcrystalline growth occurs at different SC. For higher $T_{S}$ or $T_{F}$, the transition shifts to higher SC. 

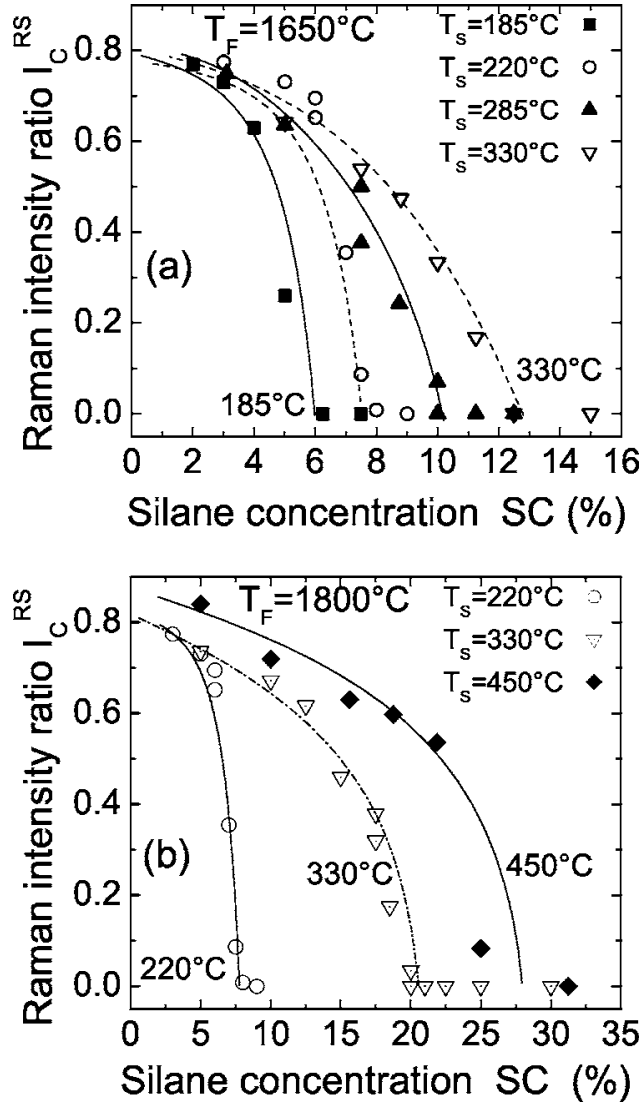

FIG. 4. Raman intensity ratio $I_{C}^{\mathrm{RS}}$ as a function of the silane concentration SC evaluated from Raman spectra for different substrate temperatures $T_{S}$. (a) shows the results for $T_{F}=1650{ }^{\circ} \mathrm{C}$, (b) shows the results for $T_{F}$ $=1800{ }^{\circ} \mathrm{C}$.

Many material properties (e.g., conductivity and hydrogen content) depend on the structural composition of the films. The structural composition can be very different for material prepared with similar SC under different deposition conditions, which makes the comparison of the material properties difficult. For this reason, the material properties of the films prepared with different deposition conditions are compared on the basis of the Raman intensity ratio $I_{C}^{\mathrm{RS}}$. In the course of this article, the term " $\mu \mathrm{c}-\mathrm{Si}: \mathrm{H} / a-\mathrm{Si}: \mathrm{H}$ transition" will be used repeatedly and, therefore, is now defined more precisely: The $\mu \mathrm{c}-\mathrm{Si}: \mathrm{H} / a-\mathrm{Si}: \mathrm{H}$ transition is the point, where the crystalline peak disappears in the Raman spectra. The silane concentration at this point is denoted with $\mathrm{SC}_{t}$ for each given combination of other parameters. This point can easily be extrapolated from the plots of $I_{C}^{\mathrm{RS}}$ vs SC due to the steep slope near the transition. The term "near" or "close to" the $\mu \mathrm{c}-\mathrm{Si}: \mathrm{H} / a-\mathrm{Si}: \mathrm{H}$ transition denotes material prepared with $\mathrm{SC}$ slightly smaller than $\mathrm{SC}_{t}$, typically leading to films with $I_{C}^{\mathrm{RS}} \leqslant 0.5$.

\section{Infrared spectroscopy}

Infrared spectroscopy is applied to gain information about the hydrogen content and the hydrogen-bonding structure. IR-absorption spectra for a sample series prepared at a high $T_{S}$ of $450{ }^{\circ} \mathrm{C}$ are shown in Fig. 5. We identify all the well-known absorption modes of $\mathrm{SiH}_{n}(n=1-3)$ in amorphous or microcrystalline silicon. The $\mathrm{SiH}$ wagging mode at

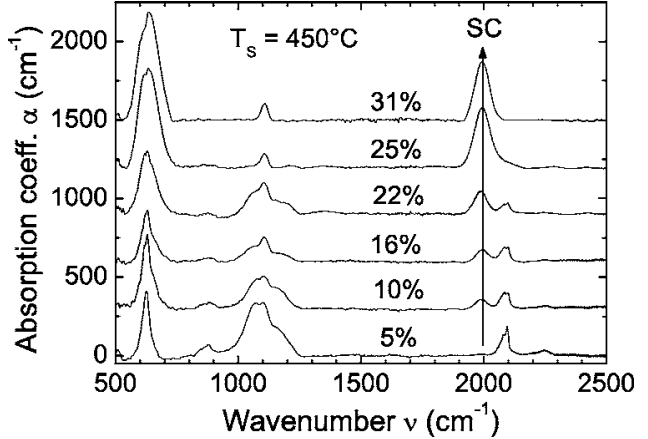

FIG. 5. Infrared absorption spectra of $\mu \mathrm{c}-\mathrm{Si}: \mathrm{H}$ films prepared at $T_{S}$ $\approx 450{ }^{\circ} \mathrm{C}$ with different SC. The individual spectra are shifted for clarity.

$630 \mathrm{~cm}^{-1}$ is found in all samples. Its intensity increases with increasing SC and the position shifts to $640 \mathrm{~cm}^{-1}$ in the amorphous sample with $\mathrm{SC}=31 \%$. For material prepared with $\mathrm{SC}=5 \%-22 \%$, the characteristic $\mathrm{SiH}$-stretching doublet of $\mathrm{SiH}$ on internal crystalline surfaces at $2100 \mathrm{~cm}^{-1}$ can be seen. ${ }^{49}$ The stretching mode at $2000 \mathrm{~cm}^{-1}$ develops at the cost of the doublet at $2100 \mathrm{~cm}^{-1}$ with increasing SC, indicating increasing amorphous contributions. At $\mathrm{SC}=31 \%$, the $\mathrm{SiH}$ surface doublet has completely disappeared. The $\mathrm{SiO}$ absorption bands, between 960 and $1150 \mathrm{~cm}^{-1}$, which are considered as an indication for porous material, are particularly strong in material with high crystalline volume fraction. The peak at $2250 \mathrm{~cm}^{-1}$, originating from $\mathrm{HSiO}_{3}$, is visible in these films too. The sharp feature at $\approx 1100 \mathrm{~cm}^{-1}$, clearly visible in the films prepared with $\mathrm{SC}=16 \%-31 \%$ originates from the crystalline silicon substrates which are covered with a native oxide. The transmission spectra of different pieces from a single wafer show deviations exactly in this region which interfere with the absorption spectra of the films.

At lower substrate temperatures, shown in Fig. 6 for $\mu \mathrm{c}-\mathrm{Si}: \mathrm{H}$ films prepared near the transition to amorphous growth, the intensity of the $630-\mathrm{cm}^{-1} \mathrm{SiH}$ wagging mode increases continuously with decreasing $T_{S}$. The intensity of the $\mathrm{SiH}$ stretching mode at $2000 \mathrm{~cm}^{-1}$ increases, while the stretching mode at $2100 \mathrm{~cm}^{-1}$ decreases, indicating a more compact structure of the material prepared at lower $T_{S}$. Simultaneously, the $\mathrm{SiO}$ absorption modes disappear at substrate temperatures below $300{ }^{\circ} \mathrm{C}$. The width of the $\mathrm{SiH}$ modes increases with decreasing substrate temperature. The

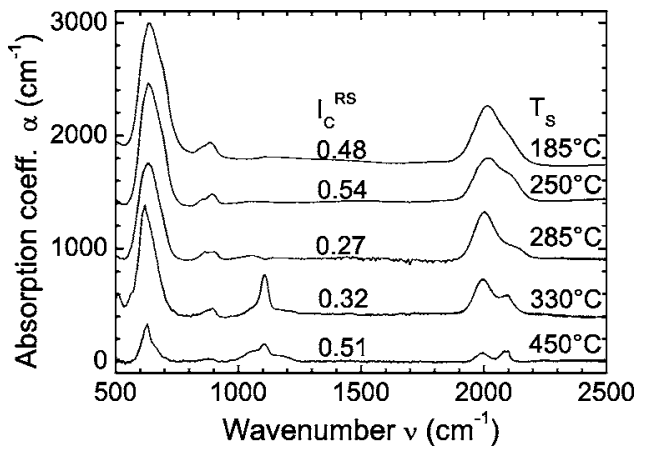

FIG. 6. Infrared absorption spectra of $\mu \mathrm{c}-\mathrm{Si}: \mathrm{H}$ films close to the transition to $a$-Si:H-growth prepared with different substrate temperatures $T_{S}$ between 185 and $450{ }^{\circ} \mathrm{C}$. The individual spectra are shifted for clarity. 


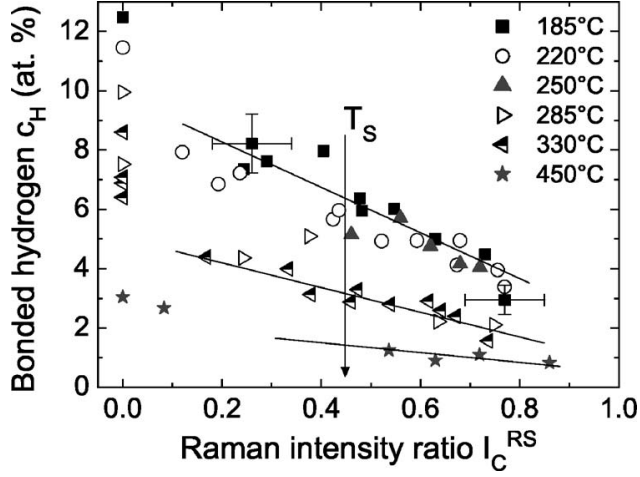

FIG. 7. Hydrogen content $c_{H}$ as a function of the Raman intensity ratio $I_{C}^{\mathrm{RS}}$ of films prepared at different substrate temperatures $T_{S}$.

trends upon a variation of SC described for $T_{S}=450{ }^{\circ} \mathrm{C}$ (Fig. 5 ) are observed for all other substrate temperatures, too.

\section{Hydrogen content}

The hydrogen content $c_{H}$ was estimated from the intensity of the absorption line at $630 / 640 \mathrm{~cm}^{-1}$ using the evaluation method developed for $a$-Si:H and extended for the application in $\mu \mathrm{c}-\mathrm{Si}: \mathrm{H}^{43,50}$ Figure 7 shows $c_{H}$ as a function of the Raman intensity ratio $I_{C}^{\mathrm{RS}}$ for films prepared with various $\mathrm{SC}$ at different substrate temperatures $T_{S}$. In this way, the comparison of films with similar structural composition is possible, e.g., material near the $\mu \mathrm{c}-\mathrm{Si}: \mathrm{H} / a-\mathrm{Si}: \mathrm{H}$ transition or highly crystalline films can be compared with each other, although they are prepared with very different silane concentrations. For a constant substrate temperature, the hydrogen content increases with decreasing $I_{C}^{\mathrm{RS}}$, i.e., the hydrogen content increases with an increasing amorphous volume fraction in the material. At $T_{S}=185^{\circ} \mathrm{C}\left(450{ }^{\circ} \mathrm{C}\right), c_{H}$ increases from 3 at. $\%(0.8$ at. $\%)$ in a highly crystalline film to 12.5 at. \% (3 at. \%) in an amorphous film. For a fixed Raman intensity ratio $I_{C}^{\mathrm{RS}}, c_{H}$ decreases with increasing $T_{S}$. Below $T_{S}$ $=250{ }^{\circ} \mathrm{C}$ only small changes of $c_{H}$ are observed, at $T_{S}$ above $285^{\circ} \mathrm{C}, c_{H}$ decreases rapidly. $\mu \mathrm{c}-\mathrm{Si}: \mathrm{H}$ containing only about 1 at. \% hydrogen is obtained at $T_{S}=450{ }^{\circ} \mathrm{C}$. Note, that this method only determines the amount of bonded hydrogen. There are, however, indications for a considerable amount of molecular hydrogen in $\mu \mathrm{c}-\mathrm{Si}: \mathrm{H}^{43,50}$

\section{Microstructure factor $\boldsymbol{R}$}

The substrate temperature determines not only the total amount of bonded hydrogen, $T_{S}$ has also a strong influence on the bonding structure and the location of the hydrogen, which can be deduced from the distribution of the $\mathrm{SiH}$ stretching modes. The microstructure factor $R$, defined by the ratio of the $\mathrm{SiH}$ stretching mode at $2100 \mathrm{~cm}^{-1}$ to the total intensity of the stretching modes (2000 and $2100 \mathrm{~cm}^{-1}$ ), can be used as a measure for the bonding structure and location of hydrogen. The evaluation of $R$ is difficult as the width and position of the peaks depend on the deposition conditions, in particular, on $T_{S} \cdot{ }^{51,52}$ Thus, the width [full width at half maximum (FWHM)] of the 2000- $\mathrm{cm}^{-1}$ peak increases from $50 \mathrm{~cm}^{-1}$ at $T_{S}=450{ }^{\circ} \mathrm{C}$ to $100 \mathrm{~cm}^{-1}$ at $T_{S}=220{ }^{\circ} \mathrm{C}$, and the width of the $2100-\mathrm{cm}^{-1}$ peak from 30 to $65 \mathrm{~cm}^{-1}$ (see Fig.

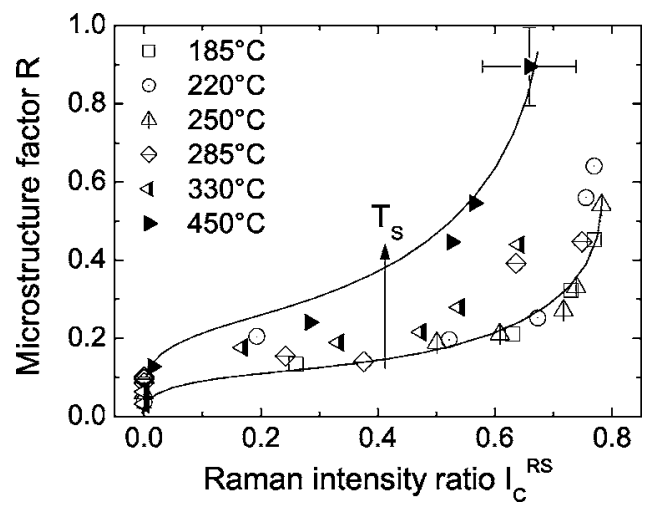

FIG. 8. Microstructure factor $R$ as a function of the Raman intensity ratio $I_{C}^{\mathrm{RS}}$ of $\mu \mathrm{c}-\mathrm{Si}: \mathrm{H}$ films prepared at different substrate temperatures $T_{S}$.

6). For this reason, the width of the two peaks was determined from a purely amorphous sample with a low $R$ for the $2000-\mathrm{cm}^{-1}$ mode and from a highly crystalline sample with a high $R$ for the $2100-\mathrm{cm}^{-1}$ mode for each substrate temperature. These values were then used for the fit for all samples at each substrate temperature.

The results are displayed in Fig. 8 as a function of the Raman intensity ratio $I_{C}^{\mathrm{RS}}$ for material prepared at different substrate temperatures. The microstructure factor $R$ increases with increasing $I_{C}^{\mathrm{RS}}$ for all substrate temperatures. The amorphous films have a significantly lower $R$ than any microcrystalline film prepared at the same $T_{S}$. $R$ remains nearly constant for $\mu \mathrm{c}$-Si:H with low crystallinity $\left(0<I_{C}^{\mathrm{RS}} \leqq 0.6\right)$ and shows a strong increase at high crystallinities $\left(I_{C}^{\mathrm{RS}} \gtrsim 0.6\right)$. Compared to low $T_{S}, R$ increases significantly at higher $T_{S}$ $\left(T_{S}=330\right.$ and $\left.450{ }^{\circ} \mathrm{C}\right)$, independent of $I_{C}^{\mathrm{RS}}$. The strong increase of $R$, observed for high crystallinities, is shifted to lower $I_{C}^{\mathrm{RS}} \approx 0.5$ at $T_{S}=450{ }^{\circ} \mathrm{C}$.

\section{Optical absorption}

The optical absorption of the $\mu \mathrm{c}-\mathrm{Si}: \mathrm{H}$ films prepared at various silane concentrations and substrate temperatures was investigated by PDS measurements. Figure 9(a) shows the obtained absorption spectra for samples prepared at $T_{S}$ $=285{ }^{\circ} \mathrm{C}$ with silane concentrations between $3 \%$ and $10 \%$, covering the range from highly crystalline samples (SC $=3 \%)$ to fully amorphous $(\mathrm{SC}=10 \%)$. These spectra are corrected for interference effects with a procedure that removes the fringes completely for homogeneous films. The remaining fringe patterns in most of the spectra are caused by structural inhomogeneity in growth direction. All microcrystalline samples $(\mathrm{SC}=3 \%-8.8 \%$ ) have the typical shape of $\mu \mathrm{c}-\mathrm{Si}: \mathrm{H}$, little difference between the samples is observed in the range from 1.2 to $1.8 \mathrm{eV}$. At higher photon energies the absorption coefficient $\alpha$ increases systematically with SC, mainly due to an increasing amorphous fraction in the material until the absorption of $a$-Si:H is reached, like in the film prepared with $\mathrm{SC}=10 \%$. The absorption below the crystalline band gap remains nearly unchanged for these $\mu \mathrm{c}-\mathrm{Si}: \mathrm{H}$ films, only at $\mathrm{SC}=3 \%$ a pronounced increase of the absorption coefficient occurs, indicating a significant increase of the defect 

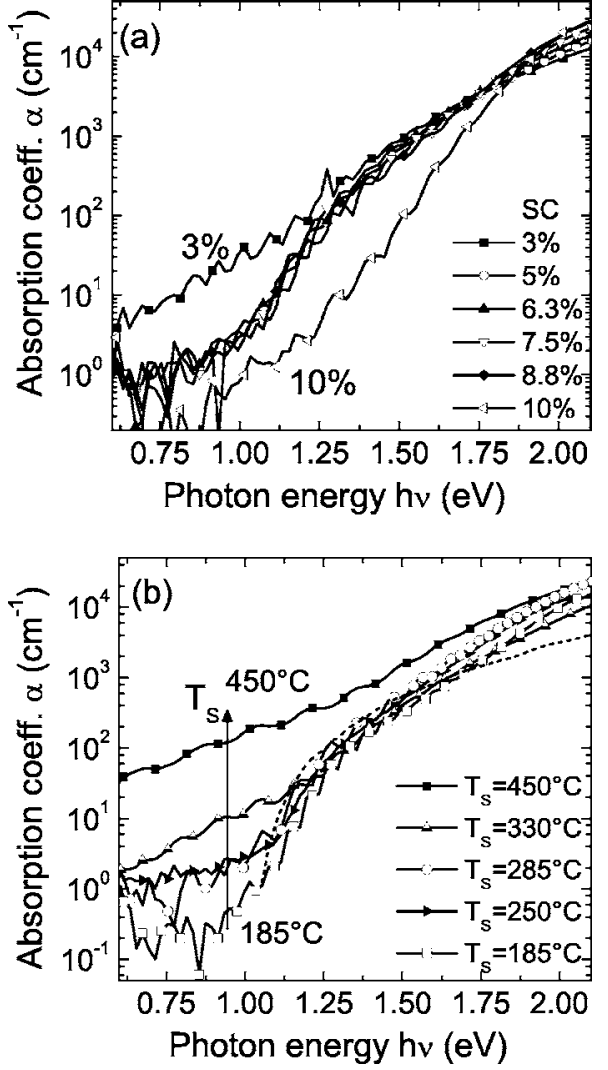

FIG. 9. Optical absorption measured by PDS of films prepared (a) at $T_{S}$ $\approx 285{ }^{\circ} \mathrm{C}$ with different silane concentrations between $3 \%$ and $10 \%$ and $(\mathrm{b})$ at different $T_{S}$ near the transition to amorphous growth.

density. The behavior of the subgap absorption is reflected in the spin densities obtained from ESR, shown in Fig. 10 versus $I_{C}^{\mathrm{RS}}$.

The influence of the substrate temperature $T_{S}$ is demonstrated in Fig. 9(b). For this purpose, films were prepared with that crystallinity, where usually the lowest subgap absorption was observed for a certain $T_{S}$ by adjusting $\mathrm{SC}$, i.e., $\mathrm{SC}$ was selected in a way such that still crystalline films, but close to the $\mu \mathrm{c}-\mathrm{Si}: \mathrm{H} / a-\mathrm{Si}: \mathrm{H}$ transition were obtained. A significant decrease of $\alpha$ below the silicon band gap is observed for a reduction of $T_{S}$. By reducing $T_{S}$ from 450 to $285^{\circ} \mathrm{C}$, $\alpha(0.8 \mathrm{eV})$ decreases by more than one order of magnitude and values of $\alpha(0.8 \mathrm{eV})<1 \mathrm{~cm}^{-1}$ are obtained. A reduction of $T_{S}$ to $185^{\circ} \mathrm{C}$ reduces the absorption in the subgap region further.

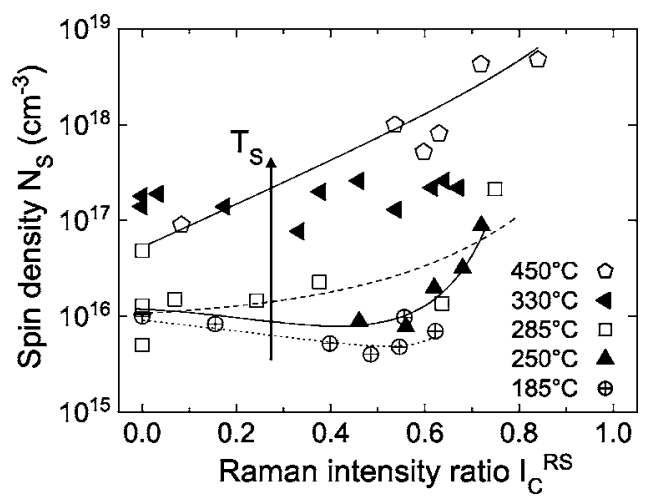

FIG. 10. Spin densities measured by ESR vs Raman intensity ratio $I_{C}^{\mathrm{RS}}$ for samples prepared at various substrate temperatures $T_{S}$.

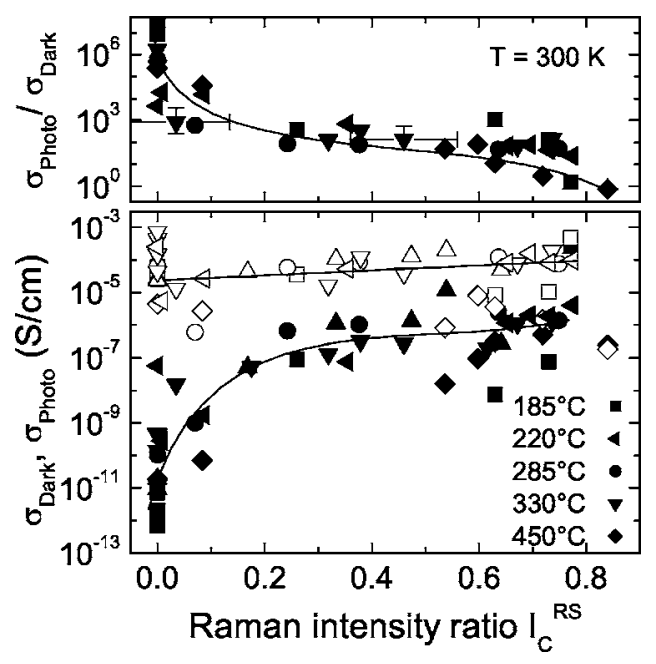

FIG. 11. Dark and photoconductivities $\sigma_{\text {Dark }}$ (full symbols) and $\sigma_{\text {Photo }}$ (open symbols) of material prepared at various $T_{S}$ as a function of the Raman intensity ratio $I_{C}^{\mathrm{RS}}$. The upper graph shows the resulting photosensitivities $\sigma_{\text {Photo }} / \sigma_{\text {Dark }}$.

\section{Electron spin resonance}

The spin densities $N_{S}$ obtained from numerical integration of the ESR spectra (i.e., without deconvolution into individual line contributions) are summarized in Fig. 10 in a plot versus $I_{C}^{\mathrm{RS}}$. The highest spin densities are usually found in a material with the highest crystalline fraction. Material prepared with medium $I_{C}^{\mathrm{RS}}$ shows only small changes of $N_{S}$ at a given $T_{S}$. The strong increase of $N_{S}$ observed at high $I_{C}^{\mathrm{RS}}$ for some samples (e.g., $T_{S}=285{ }^{\circ} \mathrm{C}$ or $T_{S}=250{ }^{\circ} \mathrm{C}$ ) could be partially caused by the exposure to water and air during the sample preparation procedure (etching of the Al foil with $\mathrm{HCl}$, rinsing the remaining powder in de-ionized water and drying in ambient air). Samples prepared on molybdenum instead of aluminum did not show such a strong increase of $N_{S} \cdot{ }^{53}$ Unlike for PECVD material, ${ }^{18}$ no further decrease of $N_{S}$ occurs by the transition to amorphous material. Independent of the crystallinity of the material, a very significant decrease of $N_{S}$ by about two orders of magnitude occurs upon a decrease of $T_{S}$ from 450 to $185^{\circ} \mathrm{C}$. The lowest spin density of $N_{S}=4 \times 10^{15} \mathrm{~cm}^{-3}$ for $\mu \mathrm{c}-\mathrm{Si}: \mathrm{H}$ prepared by HWCVD is obtained at $T_{S}=185^{\circ} \mathrm{C}$ and $I_{C}^{\mathrm{RS}} \approx 0.5$. Under similar conditions, solar cells with record efficiencies of $\eta$ =9.4\% were obtained (see Fig. 19 and Ref. 21). The spin densities observed for low $T_{S}$ are similar to those previously measured in $\mu \mathrm{c}-\mathrm{Si}: \mathrm{H}$ prepared by PECVD. ${ }^{8,54}$ The increase of $N_{S}$ for high $T_{S}$ was observed for PECVD material too. ${ }^{8,18}$ The subgap absorption and $N_{S}$ show a similar behavior upon a variation of $T_{S}$ or SC, suggesting a direct correlation between the subgap absorption and $N_{S}$.

\section{Conductivity}

Dark and photoconductivities of SC series prepared at different substrate temperatures are shown in the lower graph of Fig. 11 versus the Raman intensity ratio $I_{C}^{\mathrm{RS}}$. For all $T_{S}$, a weak increase of $\sigma_{\text {Dark }}$ with increasing $I_{C}^{\mathrm{RS}}$ is observed for microcrystalline films with $I_{C}^{\mathrm{RS}}>0.2$. At lower $I_{C}^{\mathrm{RS}}, \sigma_{\text {Dark }}$ drops by several orders of magnitude to values below $10^{-10} \mathrm{~S} / \mathrm{cm}$, typical values for amorphous material. $\sigma_{\text {Photo }}$ 
shows also a continuous increase with increasing $I_{C}^{\mathrm{RS}}$, but the magnitude is much smaller compared to the change of $\sigma_{\text {Dark }}$. This results in the highest photosensitivities $\sigma_{\text {Photo }} / \sigma_{\text {Dark }}$ for $\mu \mathrm{c}-\mathrm{Si}: \mathrm{H}$ near the transition to amorphous growth, as shown in the upper graph of Fig. 11.

The observed dark conductivities of most $\mu \mathrm{c}-\mathrm{Si}: \mathrm{H}$ samples are comparable to that of crystalline silicon. However, the typical electron mobilities of $\mu \mathrm{c}-\mathrm{Si}: \mathrm{H}$ are only a few $\mathrm{cm}^{2} / \mathrm{V} \mathrm{s}$ (compared to $\mu_{\mathrm{c}-\mathrm{Si}}=1500 \mathrm{~cm}^{2} / \mathrm{V} \mathrm{s}$ ), ${ }^{55,56}$ thus the dark conductivities are much higher than what one would expect for intrinsic $\mu \mathrm{c}-\mathrm{Si}: \mathrm{H}$. This enhanced dark conductivity is probably caused by unintentional doping. ${ }^{57}$ In spite of the large scatter of the samples, systematically lower values for $\sigma_{\text {Dark }}$ are found only for $T_{S}=450{ }^{\circ} \mathrm{C}$ and for $T_{S}=185^{\circ} \mathrm{C}$. In the case of the high-temperature material, the reduced $\sigma_{\text {Dark }}$ is probably due to the pinning of the Fermi level by the much lighter defect density, as detected by ESR and optical absorption. The high defect density leads also to a reduction of the photogenerated charge-carrier lifetime, which cause the low photosensitivity. The low $\sigma_{\text {Dark }}$ of the material prepared at $T_{S}=185{ }^{\circ} \mathrm{C}$ cannot be attributed to a high defect density. Instead, a lower impurity level or a lower mobility caused by grain boundaries has to be considered.

The drop of $\sigma_{\text {Dark }}$ around $I_{C_{5859}}^{\mathrm{RS}}=0.2$ fits well to the expectations of percolation transport, ${ }^{58,59}$ predicting a microcrystalline transport behavior for crystallinities above $30 \%$ and the transition to an amorphous silicon like behavior at lower $I_{C}^{\mathrm{RS}}$.

\section{Influence of the deposition pressure and the filament temperature}

Low substrate temperatures were identified as a prerequisite for high material quality in Sec. III B 6. However, the deposition rates at low substrate temperatures were limited by the thermal radiation of the filaments. Therefore, the influence of the deposition pressure $p_{D}$ and the filament temperature $T_{F}$ was investigated in order to obtain higher deposition rates. For this purpose, the substrate temperature was kept constant by selecting two different filament configurations which result in comparable radiation, i.e., two filaments were used at $T_{F}=1800{ }^{\circ} \mathrm{C}$ and three filaments were used at $T_{F}=1650{ }^{\circ} \mathrm{C}$. The deposition pressure has only a minor influence on $T_{S}$ : at the highest $p_{D}$, the obtained $T_{S}$ was approximately $10{ }^{\circ} \mathrm{C}$ lower than at low $p_{D}$. The influence of different filament configurations was recently investigated in another study ${ }^{47}$ and is not addressed here.

\section{Deposition rates}

The influence of the deposition pressure on the deposition rates is shown in Fig. 12. For constant SC, a monotonic increase of $r_{d}$ with increasing $p_{D}$ is observed. A saturation of $r_{d}$ is not seen in the investigated pressure range between 3 and $20 \mathrm{~Pa}$ as it was previously observed for the deposition of $a-\mathrm{Si}: \mathrm{H}^{60}$ The dependence on the deposition pressure is stronger for low $\mathrm{SC}$, at $\mathrm{SC}=2 \%$ a nearly linear relation occurs. At $\mathrm{SC}=6 \%$ a relation according to $r_{d} \propto \sqrt{p_{D}}$ is found as

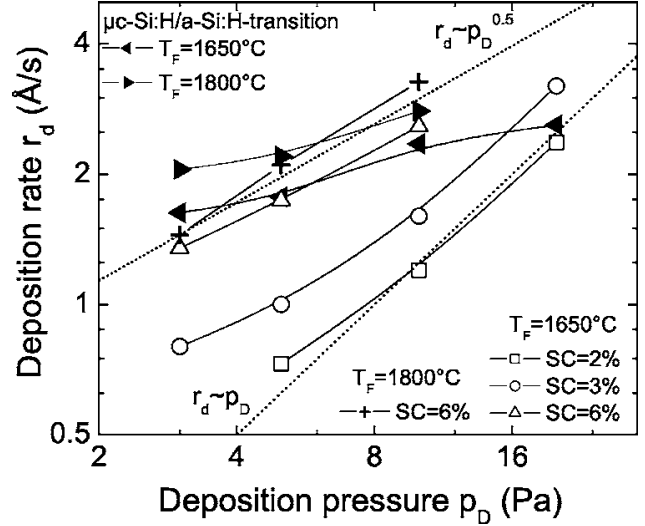

FIG. 12. Double logarithmic plot of the deposition rates as a function of the deposition pressure $p_{D}$ for constant silane concentrations ( $\mathrm{SC}=2 \%, 3 \%$, and $6 \%$ ) at $T_{F}=1650{ }^{\circ} \mathrm{C}$ and three filaments (open symbols) and $\mathrm{SC}=6 \%$ at $T_{F}=1800{ }^{\circ} \mathrm{C}$ and two filaments $(+)$ and for $\mu \mathrm{c}-\mathrm{Si}: \mathrm{H}$ near the $\mu \mathrm{c}-\mathrm{Si}: \mathrm{H} / \mathrm{a}-\mathrm{Si}: \mathrm{H}$ transition for two different filament temperatures (full symbols). The substrate temperature was $220^{\circ} \mathrm{C}$ for all samples.

observed for $a$-Si:H deposition. ${ }^{28}$ A higher $T_{F}$ of $1800{ }^{\circ} \mathrm{C}$ results in higher $r_{d}$ at the same SC despite the smaller filament surface area used here.

With increasing pressure, a structural transition from $\mu \mathrm{c}-\mathrm{Si}: \mathrm{H}$ to $a$-Si:H growth occurs for a given $\mathrm{SC}$, that means lower SC must be applied at higher $p_{D}$ in order to grow $\mu \mathrm{c}-\mathrm{Si}: \mathrm{H}$. Therefore, the increase of the deposition rate obtained by the increase of $p_{D}$ is partly compensated by the lower SC. The deposition rates achieved for $\mu \mathrm{c}-\mathrm{Si}: \mathrm{H}$ near the transition to amorphous growth are shown in addition (full symbols). Note that these points were obtained with different SC (compare also next paragraph). Only small increases of $r_{d}$ are achieved by an increase of $p_{D}$, whereas an increase of $T_{F}$ from 1650 to $1800{ }^{\circ} \mathrm{C}$ leads to a significant increase of $r_{d}$ despite the use of only two filaments.

\section{Raman spectroscopy}

$p_{D}$ and $T_{F}$ have a similar effect on the crystallinity of the material as previously observed for a variation of $T_{S}$ (compare Fig. 4). This is shown in Figs. 13(a) and 13(b) for various $p_{D}$ and $T_{F}=1650{ }^{\circ} \mathrm{C}$ and $T_{F}=1800{ }^{\circ} \mathrm{C}$, respectively. As one can see, $I_{C}^{\mathrm{RS}}$ decreases with increasing $p_{D}$ for a constant $\mathrm{SC}$. Thus, the $\mu \mathrm{c}-\mathrm{Si}: \mathrm{H} / a-\mathrm{Si}: \mathrm{H}$ transition is shifted to lower SC for higher $p_{D}$ at both $T_{F}$. An increase of $T_{F}$, on the other hand, increases the crystallinity of the material prepared with the same $p_{D}$ and SC as the comparison of Figs. 13(a) and 13(b) shows. Therefore, the $\mu \mathrm{c}-\mathrm{Si}: \mathrm{H} / a-\mathrm{Si}: \mathrm{H}$ transition is shifted to higher SC at higher $T_{F}$. The deposition rate $r_{d}$ for $\mu \mathrm{c}$-Si:H-growth increases only weakly with $p_{D}$, whereas $r_{d}$ strongly increases for constant SC. The shift of the $\mu \mathrm{c}-\mathrm{Si}: \mathrm{H} /$ $a-\mathrm{Si}: \mathrm{H}$ transition to lower $\mathrm{SC}$ at higher $p_{D}$ nearly compensates the gain of $r_{d}$ obtained at higher $p_{D}$, thus only a small increase of $r_{d}$ can be obtained by the higher $p_{D}$.

\section{Infrared spectroscopy}

The IR-absorption spectra of $\mu \mathrm{c}-\mathrm{Si}: \mathrm{H}$ films prepared near the transition to amorphous growth with different deposition pressures at $T_{S}=220{ }^{\circ} \mathrm{C}$ and $T_{F}=1650{ }^{\circ} \mathrm{C}$ are shown in Fig. 14. For that purpose, SC was adjusted accordingly for 

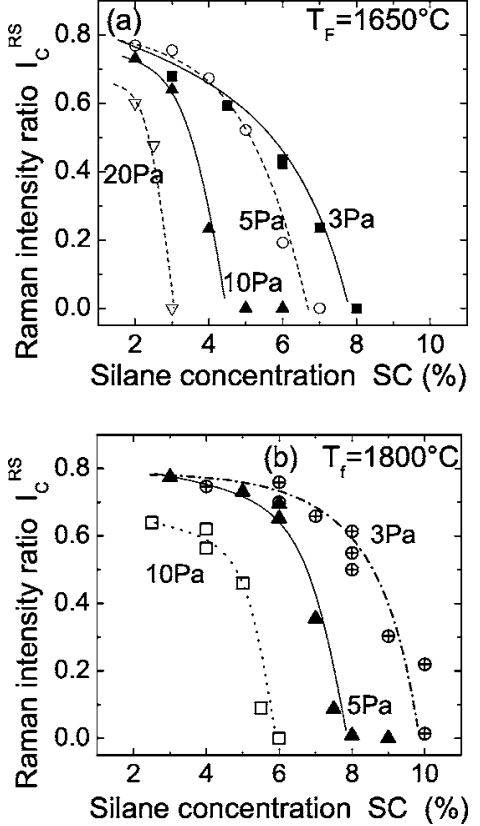

FIG. 13. Raman intensity ratio $I_{C}^{\mathrm{RS}}$ as a measure of the crystallinity vs SC for different deposition pressures $p_{D}$ and a filament temperature of (a) $T_{F}$ $=1650{ }^{\circ} \mathrm{C}$ and (b) $T_{F}=1800^{\circ} \mathrm{C}$.

each deposition pressure. The intensity of the $\mathrm{SiH}$ wagging mode remains almost constant in these films, indicating a constant hydrogen content independent of $p_{D}$. The films prepared at low $p_{D}(3$ and $5 \mathrm{~Pa})$ show no signs of a porous material structure, i.e., the $\mathrm{SiH}$-stretching modes are dominated by the $2000-\mathrm{cm}^{-1}$ peak, originating from $\mathrm{SiH}$ in a compact environment, and the $\mathrm{SiO}$ absorption peaks are almost absent. At higher $p_{D}$, the quality of the microcrystalline and amorphous material deteriorates, the $\mathrm{SiH}$ stretching mode at $2100 \mathrm{~cm}^{-1}$ grows at the expense of the $2000 \mathrm{~cm}^{-1}$, and the intensity of the $\mathrm{SiO}$ modes rises drastically. At $p_{D}=10 \mathrm{~Pa}$, the oxygen-related $\mathrm{SiH}$ stretching mode at $2250 \mathrm{~cm}^{-1}$ is emerging and is getting significantly stronger at $p_{D}=20 \mathrm{~Pa}$. Furthermore, the significant increase of the $\mathrm{SiH}_{2}$ scissor mode at $p_{D}=10$ and $20 \mathrm{~Pa}$ is evidence for a growing amount of $\mathrm{SiH}_{2}$ groups in the material. These observations lead to the assumption that a very porous structure with many voids is obtained at high $p_{D}$. This is true for all films prepared at high $p_{D}$, independent of SC and hence of the crystallinity.

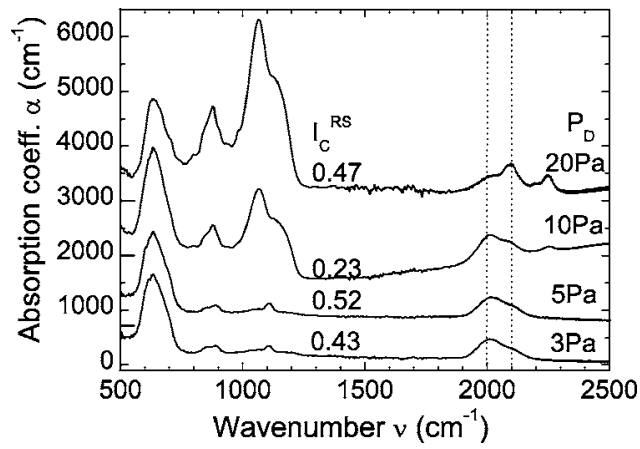

FIG. 14. Infrared absorption spectra of $\mu \mathrm{c}-\mathrm{Si}: \mathrm{H}$ films prepared with different deposition pressure $p_{D}$ between 3 and $20 \mathrm{~Pa}$ at $T_{S} \approx 220{ }^{\circ} \mathrm{C}$. The individual spectra are shifted vertically for clarity.

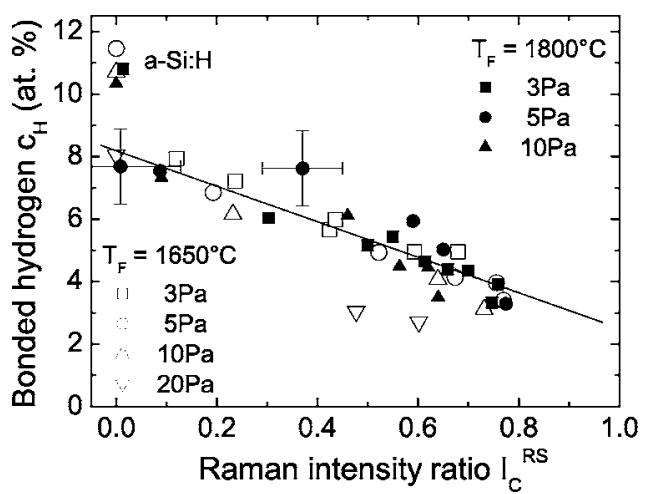

FIG. 15. Hydrogen content $c_{H}$ as a function of the crystallinity $I_{C}^{\mathrm{RS}}$ of films prepared with different $p_{D}$ at $T_{S} \approx 220^{\circ} \mathrm{C}$.

\section{Hydrogen content}

Figure 15 shows the hydrogen content $c_{H}$ for different deposition pressures $p_{D}$ and filament temperatures $T_{F}$ at a constant substrate temperature of $T_{S}=220^{\circ} \mathrm{C}$. The hydrogen content decreases linearly with increasing $I_{C}^{\mathrm{RS}}$, independent of changes in $p_{D}$ or $T_{F} . c_{H}$ of $\mu \mathrm{c}-\mathrm{Si}: \mathrm{H}$ increases from 3.5 at. $\%$ in the material with the highest crystallinity to $\approx 8$ at. $\%$ in a material close to fully amorphous growth. A hydrogen content of $11 \pm 1$ at. $\%$ is found in purely amorphous films. Some samples which appear fully amorphous in the Raman spectra have $c_{H} \approx 8 \%$. Near the $\mu \mathrm{c}-\mathrm{Si}: \mathrm{H} / a-\mathrm{Si}: \mathrm{H}$ transition, the substrate dependence of $I_{C}^{\mathrm{RS}}$ is particularly strong, i.e., films showing an entirely amorphous spectrum on glass could have some crystalline fraction if grown on a silicon substrate. However, even very small $I_{C}^{\mathrm{RS}}$ lead to significantly lower $c_{H}$ than observed in $a-\mathrm{Si}: \mathrm{H}$.

Only the $c_{H}$ values obtained for $p_{D}=20 \mathrm{~Pa}$ at $T_{F}$ $=1650{ }^{\circ} \mathrm{C}$ are systematically lower. A possible reason for this lower hydrogen content could be a lower refractive index of these samples, due to the high oxygen content and the resulting higher $A_{640}$, which should then be used. ${ }^{43}$ Another reason for a higher $R$ could be changes of the dipole moment of the $\mathrm{SiH}$ bond due to the negative charge of the oxygen backbond.

\section{Microstructure factor $R$}

Figure 16 displays the microstructure factor $R$ of films prepared with $T_{F}=1650{ }^{\circ} \mathrm{C}$ and $T_{F}=1800{ }^{\circ} \mathrm{C}$ and various

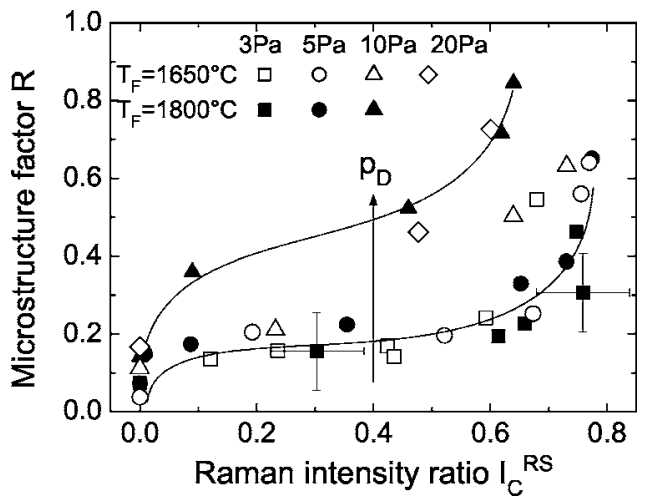

FIG. 16. Microstructure factor $R$ as a function of the Raman intensity ratio $I_{C}^{\mathrm{RS}}$ of the $\mu \mathrm{c}-\mathrm{Si}: \mathrm{H}$ films prepared with different deposition pressures $p_{D}$ at $T_{S} \approx 220^{\circ} \mathrm{C}$. 


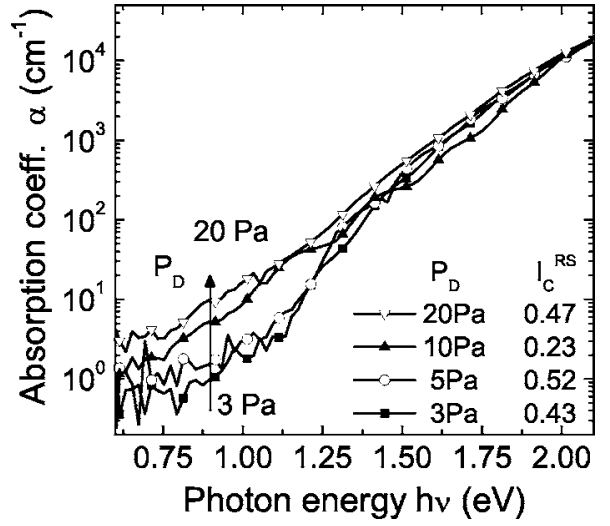

FIG. 17. Optical absorption measured by PDS of $\mu \mathrm{c}-\mathrm{Si}: \mathrm{H}$ films prepared near the transition to amorphous growth with different $p_{D}$ at $T_{S} \approx 220{ }^{\circ} \mathrm{C}$ and $T_{F}=1650^{\circ} \mathrm{C}$.

deposition pressures as a function of $I_{C}^{\mathrm{RS}} \cdot R$ is always lowest for fully amorphous material and increases continuously with $p_{D}$. At medium crystallinity $\left(I_{C}^{\mathrm{RS}}<0.6\right)$, material with low $R$ (below 0.2 ) can be obtained at $p_{D}=3$ and $5 \mathrm{~Pa}$ for both $T_{F}$. For $T_{F}=1650{ }^{\circ} \mathrm{C}$, an increase of $R$ is found for highly crystalline material at $p_{D}=10 \mathrm{~Pa}$, while the material prepared at $p_{D}=20 \mathrm{~Pa}$ exhibits high $R$ for all crystallinities, even for completely amorphous material. At $T_{F}=1800{ }^{\circ} \mathrm{C}$ and $p_{D}$ $=10 \mathrm{~Pa}$, much higher $R$ values are obtained for all $I_{C}^{\mathrm{RS}}$.

In spite of the similar behavior of $R$ for increasing $p_{D}$ and $T_{S}$, there is still a systematic difference in the IRabsorption spectra of these samples. The $\mathrm{SiH}_{2}$ scissor modes around $850 \mathrm{~cm}^{-1}$ (compare Fig. 14) increase drastically with increasing deposition pressure but do not show any significant change for an increasing substrate temperature (see Fig. 6). The intensity of these $\mathrm{SiH}_{2}$ scissor modes was found to be almost independent of the silane concentration and hence of the crystalline fraction of the material.

\section{Optical absorption}

The influence of the deposition pressure $p_{D}$ on the optical absorption is demonstrated in Fig. 17. For that purpose, films with a moderate crystallinity (the same films as for the IR spectra in Fig. 14) were selected, because the lowest subgap absorption is typically obtained for such films near the $\mu \mathrm{c}-\mathrm{Si}: \mathrm{H} / a-\mathrm{Si}: \mathrm{H}$ transition. A significant decrease of $\alpha$ below the crystalline silicon band gap is observed for a reduction of $p_{D}$. By reducing the deposition pressure from 20 to $3 \mathrm{~Pa}$, $\alpha(0.7 \mathrm{eV})$ decreases from 9 to $0.9 \mathrm{~cm}^{-1}$ for films prepared with $T_{F}=1650{ }^{\circ} \mathrm{C}$ at $T_{S}=220{ }^{\circ} \mathrm{C}$. A similar behavior was observed for films prepared with $T_{F}=1800{ }^{\circ} \mathrm{C}$ and for films prepared at $T_{S}=450{ }^{\circ} \mathrm{C}$. The latter show a decrease from $\alpha$ $=40 \mathrm{~cm}^{-1}$ at $10 \mathrm{~Pa}$ to $\alpha=3 \mathrm{~cm}^{-1}$ at $2 \mathrm{~Pa}$. Simultaneously, the spin density of these films increases from $2.3 \times 10^{17}$ to 3.4 $\times 10^{18} \mathrm{~cm}^{-3}$ at $10 \mathrm{~Pa}$.

\section{Properties of solar cells}

The development of thin-film solar cells is the main application for our $\mu \mathrm{c}-\mathrm{Si}: \mathrm{H}$ research, therefore the performance of the prepared material in thin-film solar cells is of great relevance. Solar cells are very sensitive to the material prop-

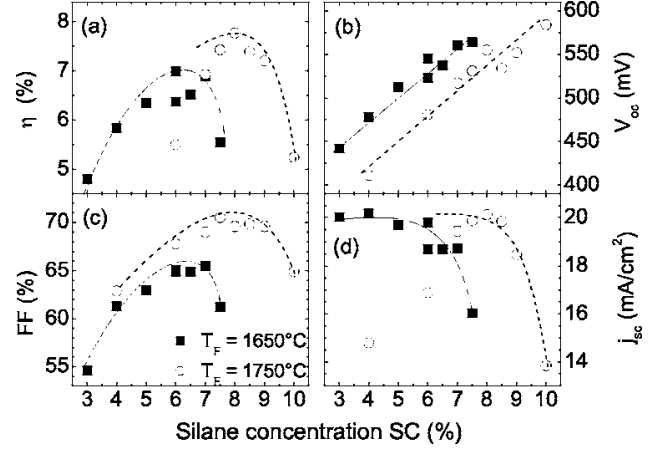

FIG. 18. Electrical parameters of $1-\mu \mathrm{m}$-thick $p-i-n$ solar cells prepared with filament temperatures of $T_{F}=1650^{\circ} \mathrm{C}$ and $T_{F}=1750{ }^{\circ} \mathrm{C}$ at a substrate temperature of $T_{S} \approx 220{ }^{\circ} \mathrm{C}$ and $T_{S} \approx 210{ }^{\circ} \mathrm{C}$, respectively as a function of SC. (a) efficiency $\eta$, (b) open circuit voltage $V_{\text {oc }}$, (c) fill factor FF and (d) short circuit current-density $j_{\mathrm{sc}}$. Lines are guide to the eye.

erties and small changes of, e.g., spin density or microstructure, are reflected in large changes of the solar cell parameters, in particular, the dark saturation current density $j_{0}$ or the open circuit voltage $V_{\mathrm{oc}}$. Therefore, additional information on the electronic properties can be obtained by a careful analysis of solar cell parameters.

\section{Influence of the silane concentration}

The electrical parameters under illumination for two series of $p-i-n$ solar cells are shown in Fig. 18 as a function of the silane concentration SC. The short circuit current densities $j_{\mathrm{sc}}$ reach values around $20 \mathrm{~mA} / \mathrm{cm}^{2}$ for solar cells prepared with low SC and sharply decrease at the transition to amorphous growth, taking place at $\mathrm{SC} \approx 7 \%$ with $T_{F}$ $=1650{ }^{\circ} \mathrm{C}$ and at $\mathrm{SC} \approx 9 \%$ with $T_{F}=1750{ }^{\circ} \mathrm{C}$ [compare Fig. 18(d)]. The deposition time for the low SC values (particularly $4 \%$ and $6 \%$ ) at $T_{F}=1750{ }^{\circ} \mathrm{C}$ was not sufficiently adjusted, resulting in too thin devices with low $j_{\mathrm{sc}}$ and $\eta$. The efficiency $\eta$ [Fig. 18(a)] and the fill factor (FF) [Fig. 18(c)] increase with $\mathrm{SC}$, reach a maximum, and decrease at the highest SC of each series, while the open circuit voltage [Fig. 18(b)] increases almost linearly with SC over the entire SC range. $V_{\mathrm{oc}}$ of around $560 \mathrm{mV}$ were obtained in solar cells with the highest efficiency for both filament temperatures at deposition rates of 1.5 and $2.5 \AA / s$, respectively. The lower absolute FF values for the cells prepared with low $T_{F}$ probably originate from the slightly higher substrate temperatures arising by the radiant heat of the three filaments, leading to a deterioration of the $p / i$ interface. $J-V$ measurements with blue and orange filters support this interpretation of the low FF. With the blue filter, emphasizing the generation at the $p / i$ interface, the FF is further reduced, while the use of the orange filter, creating a homogeneous generation across the $i$ layer, improves the FF to $69 \%$.

The same trends upon a variation of SC as described above were observed for many other SC series which were prepared in different deposition regimes, applying lower substrate temperatures, different filament temperatures, and different deposition pressures. At $T_{S} \approx 185^{\circ} \mathrm{C}$ and low deposition pressure, solar cells with the highest efficiencies, $V_{\text {oc }}$ up to $600 \mathrm{mV}$, and $\mathrm{FF}$ above $72 \%$ were obtained. ${ }^{22}$ 


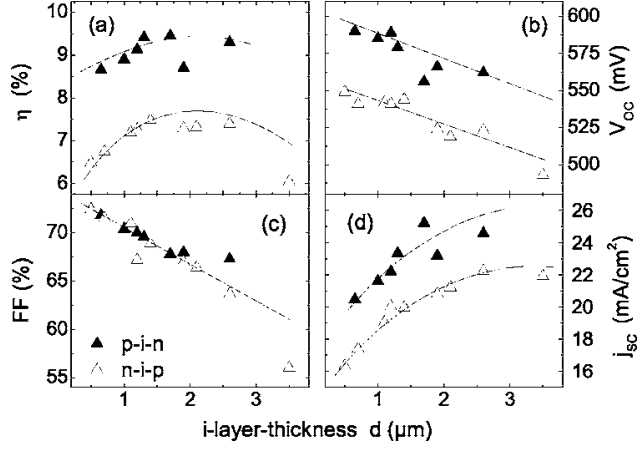

FIG. 19. $J$ - $V$ parameters of $p-i-n$ (closed symbols) and $n-i-p$ (open symbols) solar cells prepared with a $\mathrm{HW} i$ layer at $T_{S} \approx 185{ }^{\circ} \mathrm{C}$ and $T_{S} \approx 260{ }^{\circ} \mathrm{C}$, respectively. (a) efficiency $\eta$, (b) open circuit voltage $V_{\mathrm{oc}}$, (c) fill factor FF, and (d) short circuit current-density $j_{\mathrm{sc}}$. Lines are guide to the eye.

\section{Thickness dependence}

The excellent performance of solar cells prepared at low substrate temperatures is demonstrated in Fig. 19, showing the $J-V$ parameters of $p-i-n$ and $n-i-p$ solar cells as a function of the $i$-layer thickness. The $p-i-n$ solar cells reach very high efficiencies of $\eta \approx 9.4 \%$. The high $\eta$ mainly result from the extraordinary high $V_{\mathrm{oc}}$ of $589 \mathrm{mV}$ in a $1-\mu \mathrm{m}$-thick cell and $562 \mathrm{mV}$ in a $2.6-\mu \mathrm{m}$-thick cell, together with the high $j_{\mathrm{sc}}$. The general behavior is similar for the $p-i-n$ and $n-i-p$ cells. $V_{\text {oc }}$ [Fig. 19(b)] and FF [Fig. 19(c)] decrease upon increasing thickness, while $j_{\mathrm{sc}}$ [Fig. 19(d)] increases as a result of the higher absorption in thicker cells. $j_{\mathrm{sc}}$ in the $p-i-n$ cells is approximately $4 \mathrm{~mA} / \mathrm{cm}^{2}$ higher than in the $n-i-p$ cells due to the better light-trapping structures of the applied $p-i-n$ substrates. $V_{\text {oc }}$ is approximately $40 \mathrm{mV}$ higher in the $p-i-n$ cells of the same thickness, but only $\approx 12 \mathrm{mV}$ can be attributed to the higher photocurrent in the $p-i-n$ cells. ${ }^{22}$ The combination of all these effects results in a weak thickness dependence of the efficiency $\eta$ [Fig. 19(a)] between 1 and $3 \mu \mathrm{m}$ with maximum efficiencies of $9.4 \%$ and $7.4 \%$ for $p-i$ $-n$ and $n-i-p$ solar cells, respectively, at an $i$-layer thickness of about $1.5-2 \mu \mathrm{m}$.

\section{Influence of the deposition pressure}

The strong effect of the material quality on the solar cell parameters is demonstrated by means of the influence of the deposition pressure on the $i$-layer material properties. The same deposition conditions as for the samples in Sec. III C were applied for the $i$-layer deposition.

Solar cells with $i$ layers grown near the $\mu \mathrm{c}-\mathrm{Si}: \mathrm{H} / a-\mathrm{Si}: \mathrm{H}$ transition, i.e., where the best solar cell efficiency is obtained, were prepared for various $T_{F}$ and $p_{D}$. A similar behavior upon a variation of SC as described in Fig. 18 was observed for all series. However, the maximum of FF and $\eta$ occur at different $\mathrm{SC}$ for each series and the corresponding $V_{\mathrm{oc}}$ are difficult to compare. A direct comparison of the different deposition regimes is possible by the plot of the FF and $j_{\mathrm{sc}}$ vs $V_{\mathrm{oc}}$ in Fig. 20. In order to stress the bulk properties, $j_{\mathrm{sc}}$ was measured using AM 1.5 illumination with an additional og590 filter, generating a more homogeneous absorption profile across the $i$ layer.
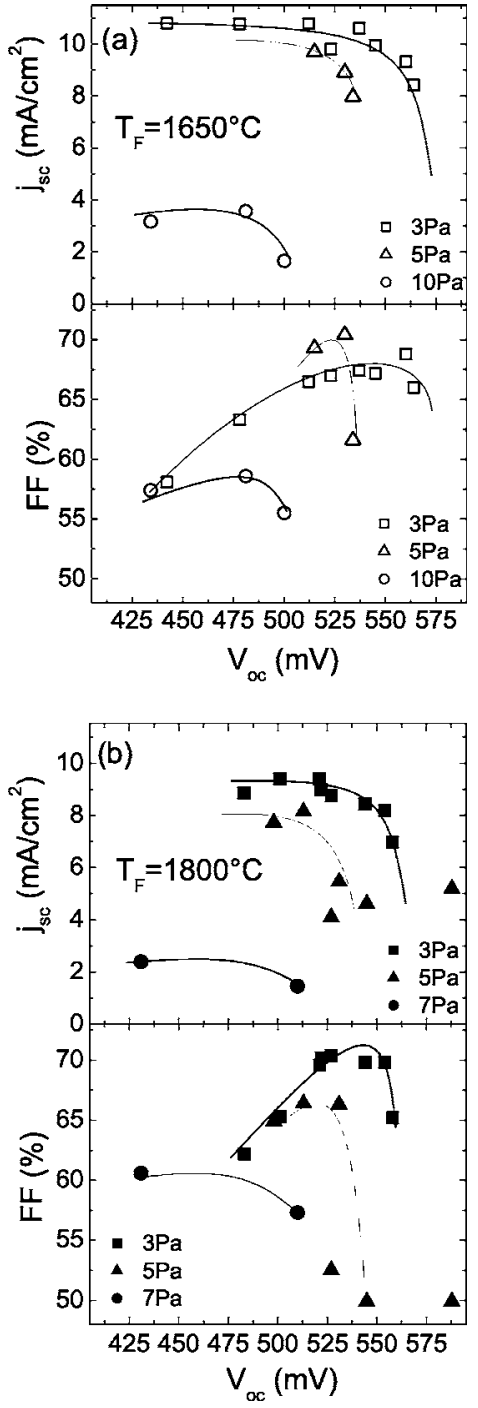

FIG. 20. $J-V$ parameters of $p-i-n$ solar cells prepared with different $T_{F}$ and $p_{D}$ at $T_{S} \approx 220{ }^{\circ} \mathrm{C}$ as a function of the open circuit voltage $V_{\mathrm{oc}}$. The short circuit current-density $j_{\mathrm{sc}}$ (top) and fill factor FF (bottom), measured under AM 1.5 illumination with an og590 filter, is displayed for solar cells prepared at $T_{F} \approx 1650{ }^{\circ} \mathrm{C}$ on the left and $T_{F} \approx 1800{ }^{\circ} \mathrm{C}$ on the right. Lines are guide to the eye.

The short circuit current density $j_{\mathrm{sc}}$ remains constant at low $V_{\text {oc }}$ for all $T_{F}$ and $p_{D}$ (i.e., depositions with low $\mathrm{SC}$ ) and starts to decrease at the transition to amorphous growth. The fill factor first increases at low $V_{\text {oc }}$ then drops at the same $V_{\text {oc }}$ as $j_{\mathrm{sc}}$. The drop of $j_{\mathrm{sc}}$ and FF occurs at higher $V_{\mathrm{oc}}$ for lower deposition pressures and the absolute values of $j_{\mathrm{sc}}$ and FF are also higher for lower $p_{D}$. At $p_{D}=3 \mathrm{~Pa}$, a $V_{\mathrm{oc}}$ of $550 \mathrm{mV}$ is obtained at full $j_{\mathrm{sc}}$ and maximum FF, while at $p_{D}=5 \mathrm{~Pa}$ only $525 \mathrm{mV}$ can be obtained. At higher pressures (10 or $7 \mathrm{~Pa}$ ), the observed fill factors and short circuit current densities are low over the entire $V_{\mathrm{oc}}$ range, so that no maximum of the fill factor or a drop of $j_{\mathrm{sc}}$ can be determined.

The dark $J-V$ properties, i.e., the dark saturation current density $j_{0}$ and the diode quality factor $n$, are directly related to the material properties and to $V_{\text {oc }}$ by the diode equation. Thus, the dark $J-V$ measurements can help to better understand the performance under illumination. $j_{0}$ and $n$ are shown in Fig. 21 as a function of $V_{\text {oc }}$ for the same solar cells as in 


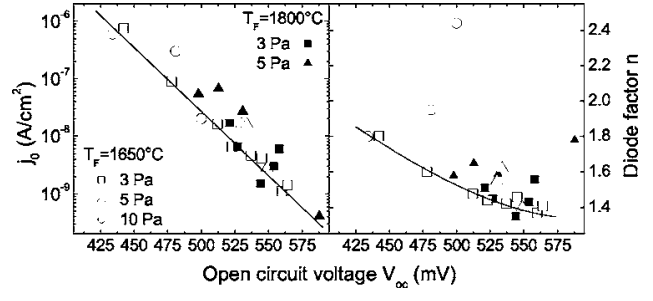

FIG. 21. Dark $J-V$ parameters of $p-i-n$ solar cells prepared at different $p_{D}$ and $T_{F}$ at $T_{S} \approx 220^{\circ} \mathrm{C}$. Dark saturation current-density $j_{0}$ on the left and diode quality factor $n$ on the right are shown as a function of the open circuit voltage $V_{\mathrm{oc}}$. Lines are guide to the eye.

Fig. 20. The dark saturation current density $j_{0}$ decreases exponentially with increasing $V_{\text {oc }}$ for all deposition conditions. No significant difference is found for the solar cells prepared with $p_{D}=3 \mathrm{~Pa}$, but at different $T_{F}$. At $p_{D}=5 \mathrm{~Pa}$, the observed $j_{0}$ are somewhat higher, especially for the solar cells which have still high FF and $j_{\mathrm{sc}}$ (around $520 \mathrm{mV}$ ). The diode quality factors $n$, shown in the right graph of Fig. 21, decrease with increasing $V_{\mathrm{oc}}$ for the cells prepared with $p_{D}=5 \mathrm{~Pa}$ and below. The increase of $n$ at high $V_{\text {oc }}$ for the individual series is linked to the high amorphous fractions in these cells. Again no significant difference of $n$ is observed in the solar cells prepared with different $T_{F}$ at $3 \mathrm{~Pa}$, the low values of $n$ around 1.4 indicate that the recombination in the bulk of these solar cells might not be the dominant recombination mechanism. At $p_{D}=5 \mathrm{~Pa}$, the observed $n$ are higher $(n$ $\approx 1.6$ ), indicating that the recombination in the bulk of the $i$ layer is becoming more important. At $p_{D}=10 \mathrm{~Pa}$ very high values for $n$ are found, caused by the poor material quality and high defect density which is obtained at this pressure.

\section{Influence of the crystallinity}

Figure 22 shows the open circuit voltage $V_{\text {oc }}$ versus the Raman intensity ratio $I_{C}^{\mathrm{RS}}$ of the solar cells of the previous paragraph prepared at $T_{S}=220{ }^{\circ} \mathrm{C}$ and for some solar cells prepared at $T_{S}=185^{\circ} \mathrm{C}$. For a fixed deposition pressure (and substrate temperature) $V_{\text {oc }}$ decreases continuously with increasing $I_{C}^{\mathrm{RS}}$, at first decreasing slowly for $I_{C}^{\mathrm{RS}}<0.4$, then more strongly for $I_{C}^{\mathrm{RS}}>0.5$. On the other hand, $j_{\mathrm{sc}}$ is almost constant at high $I_{C}^{\mathrm{RS}}$ and decreases strongly at low $I_{C}^{\mathrm{RS}}$. The FF decreases at low and high $I_{C}^{\mathrm{RS}}$ (not shown). Thus, high FF and $j_{\mathrm{sc}}$ are obtained at intermediate $I_{C}^{\mathrm{RS}}$ between 0.3 and 0.6 ,

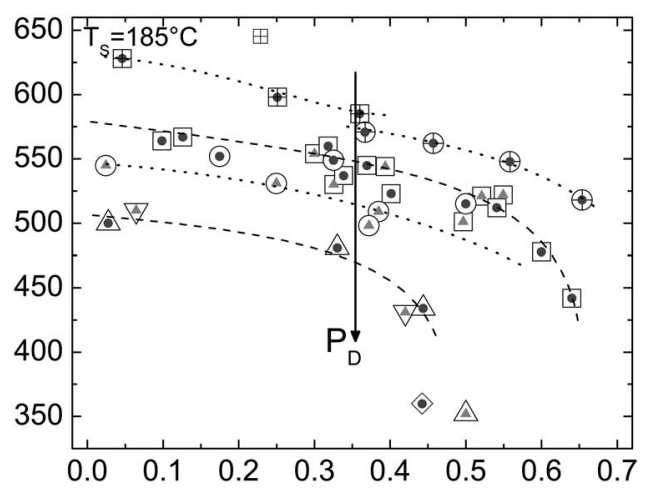

FIG. 22. Open circuit voltages of $p-i-n$ solar cells as a function of the Raman intensity ratio $I_{C}^{\mathrm{RS}}$ prepared with various $p_{D}$ and $T_{F}$ at substrate temperatures of $T_{S} \approx 220{ }^{\circ} \mathrm{C}$ (open symbols) and $T_{S} \approx 185^{\circ} \mathrm{C}(\oplus \boxplus)$. restricting the range of good solar cell performance. At a given $I_{C}^{\mathrm{RS}}$, e.g., at $I_{C}^{\mathrm{RS}}=0.4, V_{\mathrm{oc}}$ decreases for increasing $p_{D}$ caused by a higher $j_{0}$ due to the higher defect density. Or, the other way around, at lower $p_{D}$ a certain $V_{\text {oc }}$ can be obtained with higher $I_{C}^{\mathrm{RS}}$, e.g., $V_{\mathrm{oc}}=500 \mathrm{mV}$ is obtained already in a highly crystalline cell at $p_{D}=3 \mathrm{~Pa}$, but at $p_{D} \geqslant 7 \mathrm{~Pa}$ the same $V_{\text {oc }}$ can only be obtained in a nearly amorphous cell. Thereby, higher $j_{\mathrm{sc}}$ and FF at higher $V_{\mathrm{oc}}$ are possible at lower $p_{D}$. A further increase of $V_{\text {oc }}$ at a constant $I_{C}^{\mathrm{RS}}$ can be achieved by reducing the substrate temperature to $185^{\circ} \mathrm{C}$. The increase of $V_{\text {oc }}$ at fixed $I_{C}^{\mathrm{RS}}$ is correlated to the decrease of $j_{0}$, which can be attributed to an improved material quality, as the comparison with the material properties indicates.

These solar cells prepared by HWCVD exhibit exceptionally high $V_{\text {oc }}$ which are accompanied by a high amorphous volume fraction in the $i$ layer. Despite the low crystallinity, no detrimental effects on the charge-carrier extraction are observed for freshly prepared solar cells. However, upon light soaking, a Staebler-Wronski-like ${ }^{61}$ degradation is observed in solar cells with high $V_{\text {oc }}$, while highly crystalline solar cells prepared by HWCVD, or by PECVD, show only very little degradation. ${ }^{62-64}$

\section{DISCUSSION}

High deposition rates, while maintaining the high material quality, are of major interest for industrial solar cell production. To achieve this, an improved understanding of the deposition processes is necessary. A study of the influence of the individual deposition parameters on the deposition rate $r_{d}$ and the corresponding material and solar cell properties can provide valuable knowledge about the processes involved. The deposition rate strongly depends on the dissociation of silane, the crystallinity on the hydrogen dissociation, and the material quality on reactions in the gas phase. The deposition of high-quality $\mu \mathrm{c}-\mathrm{Si}: \mathrm{H}$ solar cell requires the optimization under these boundary conditions. The comparison of the material and solar cell properties demonstrates the effect of structure and defects on the device performance and shows how solar cells can be applied as sensitive device to judge the material quality.

\section{A. Deposition rates}

The deposition rate $r_{d}$ is determined by the amount of radicals impinging on the substrate and the sticking probability on the growing film surface. Consequently, $r_{d}$ is a result of the amount of radicals produced at the filaments as well as the transport of radicals and, thus, the geometry of the chamber.

According to this, the deposition rate can thus be approximated by the following equation:

$$
r_{d} \propto \frac{p_{\text {silane }}}{\sqrt{\left(2 \pi m k_{B} T_{G}\right)}} e^{-E_{A}^{\mathrm{Si}} / k_{B} T_{F}},
$$

with $p_{\text {silane }}$ the partial pressure of silane, $m$ the molecular mass of the growth radicals, $k_{B}$ Boltzmann's constant, $T_{G}$ the gas temperature, and $E_{A}^{\mathrm{Si}}$ the activation energy of the silicon dissociation. The first term includes the collision rate of $\mathrm{SiH}_{4}$ molecules with the filament according to kinetic gas theory, 
the second term gives the dissociation probability of $\mathrm{SiH}_{4}{ }^{24}$ The partial pressure of silane linearly depends on SC and $p_{D}$. For this reason, a linear increase of $r_{d}$ is expected at constant $T_{F}$. In fact, a nearly linear dependence of $r_{d}$ on SC was observed for all conditions. A linear pressure dependence was observed at low SC of $2 \%$ or $3 \%$. The collision rate is also proportional to the filament area and the enlargement of the filament surface led to the expected increase of the deposition rate. An increase of the filament temperature increases the dissociation probability of the silane molecules at the filament surface. The activation energy for the deposition rate of $1.35 \pm 0.3 \mathrm{eV}$ is in good agreement with the dissociation enthalpy $E_{A}^{\mathrm{Si}}$ of silane ${ }^{26,65}$ and the $T_{F}$ dependence of $r_{d}$ can thus be explained by the silane dissociation.

However, such a simple model neglects the influence of mass transport, reactions in the gas phase and at the film surface, and the presence of large amounts of molecular hydrogen, which can explain the deviations from the predicted behavior. A sublinear increase of $r_{d}$ at $\mathrm{SC}=6 \%$ was observed. Similar observations for the deposition of $a$-Si:H from pure silane were previously attributed to limitations by mass transport $^{60}$ if the mean free path $\left(\lambda_{\mathrm{mfp}}\right)$ is of the order of the chamber dimensions. Furthermore, reactions of $\mathrm{Si}$ radicals with silane become more frequent at higher $p_{\text {silane }}$ and produce less reactive precursors, e.g., $\mathrm{Si}_{2} \mathrm{H}_{2}$ instead of $\mathrm{Si}$. At high filament temperatures $\left(T_{F} \approx 2000{ }^{\circ} \mathrm{C}\right)$ a saturation of the deposition rate was observed for amorphous silicon, caused by the dissociation probability approaching unity. But not only the dissociation of silane, but also the hydrogen dissociation increases with increasing $T_{F}$. This can lead to two opposite effects: (i) the etching due to atomic hydrogen increases and the deposition rate decreases and (ii) the abstraction of hydrogen from $\mathrm{SiH}_{4}$ leads to additional film precursors and thus higher deposition rates.

Within the examined temperature range $\left(T_{S}\right.$ $=185-450{ }^{\circ} \mathrm{C}$ ) the substrate temperature has only a minor influence on $r_{d}$. The temperature dependence of the reaction probability or an increase of silane desorption from the film surface might account for this effect. Etching due to atomic hydrogen can be excluded because the etching rates decrease for increasing $T_{S}$.

Moreover, the geometry of the chamber and the filaments has a large impact on the deposition rate. For low pressures $\left(\lambda_{\mathrm{mfp}} \leqslant d_{\mathrm{SF}}\right)$, where $d_{\mathrm{SF}}$ is the distance between a point source and a point on the substrate, it was shown that the flux follows a $1 / d_{\mathrm{SF}}^{2}$ dependence, and the total flux can be obtained from integration along the filaments. ${ }^{24}$ Thus, large filament areas close to the substrate would be best for high deposition rates. For a homogeneous deposition, a minimum density of filaments is required which is half of the filamentsubstrate distance. ${ }^{15}$ However, such conditions also lead to substantial heating of the substrate which is detrimental for the material quality (see next sections).

\section{B. Microcrystalline material growth}

Besides the deposition rate, the regime of crystalline material growth is of great interest for high rate deposition of $\mu \mathrm{c}-\mathrm{Si}: \mathrm{H}$. The crystallinity is often adversely affected by a variation of a deposition parameter which increases $r_{d}$. The regime of crystalline material growth is limited to lower SC for lower $T_{F}$ or higher $p_{D}$ as shown in Fig. 13. This suggests that a certain amount of atomic hydrogen is required for microcrystalline silicon growth. The models describing the growth of microcrystalline silicon have in common that atomic hydrogen plays a crucial role although the specific microscopic mechanisms are rather different for these models. ${ }^{37,39,41}$

The relatively simple mechanism of radical production for the hot-wire CVD process allows some speculations about the flux of the involved radicals, namely, $\mathrm{H}$ and $\mathrm{Si}$. As reported by Umemoto et al., ${ }^{26}$ the dissociation of $\mathrm{H}_{2}$ into $\mathrm{H}$ atoms on the filament depends on the deposition pressure and filament temperature and is in good agreement with the chemical equilibrium concentrations. The reaction enthalpy for hydrogen dissociation (228 kJ/mol) (Ref. 26) is about two times higher than for silane dissociation $(100 \mathrm{~kJ} / \mathrm{mol}$ for Ta) (Ref. 25) and thus much more temperature dependent. By increasing the filament temperature, the dissociation of $\mathrm{H}_{2}$ increases much stronger than the decomposition of silane. Thus, a similar ratio of silane radicals and atomic hydrogen is obtained at a higher silane concentration for higher $T_{F}$.

The chemical equilibrium concentration of atomic $[\mathrm{H}]$ and molecular hydrogen $\left[\mathrm{H}_{2}\right]$ is given by the law of mass action:

$$
\frac{[\mathrm{H}]^{2}}{\left[\mathrm{H}_{2}\right]}=K=e^{-\Delta G / k_{B} T},
$$

with the Gibbs free-energy $\Delta G(p, T)$. The concentration of atomic hydrogen thus depends on $T_{F}$ and $p_{D}$. The decomposition of silane, on the other hand, is independent of the deposition pressure. ${ }^{60}$ The experimentally observed dissociation probability $k_{\mathrm{Si}}$ for silane with an activation energy ${ }^{25}$ of 1 $\mathrm{eV}$ and a dissociation probability of unity for $2000{ }^{\circ} \mathrm{C}$ independent of the pressure ${ }^{24,28}$ is used for the following calculations. This yields $k_{\mathrm{Si}}=0.4$ at $T_{F}=1650{ }^{\circ} \mathrm{C}$ and $k_{\mathrm{Si}}=0.6$ at $T_{F}=1800{ }^{\circ} \mathrm{C}$. The ratio $\kappa$ of silane radicals to atomic hydrogen is then given by the following equation:

$$
\kappa=\frac{k_{\mathrm{Si}} \cdot \mathrm{SC}_{t}}{k_{\mathrm{H}}\left(1-\mathrm{SC}_{t}+2 \mathrm{SC}_{t} \cdot k_{\mathrm{Si}}\right)} .
$$

$\mathrm{SC}_{t}$ is the silane concentration for the $\mu \mathrm{c}-\mathrm{Si}: \mathrm{H} /$ $a$-Si:H-transition. $k_{\mathrm{H}}$ can be derived from Eq. (7) and the $\mathrm{H}_{2}$ concentration is $1-\mathrm{SC}_{t}$ plus the hydrogen produced by the dissociated silane $\left(2 \mathrm{SC}_{t} \times k_{\mathrm{Si}}\right)$. For the actual calculation of $k_{\mathrm{H}}$ the online-calculator CHEMKIN was used. ${ }^{66}$ The results for $k_{\mathrm{H}}$ and $\kappa$ are given in Table II for the two filament temperatures and different deposition pressures at $T_{S}=220^{\circ} \mathrm{C}$. $\kappa$ is nearly identical for all pressures and exhibits only a small variation with the filament temperatures. According to these calculations, a minimum of 5.2 hydrogen atoms per produced silane radical is required for microcrystalline film growth. The deposition pressure does not influence this ratio significantly. At the higher $T_{F}$ of $1800{ }^{\circ} \mathrm{C}$, the observed $\kappa$ are approximately $25 \%$ lower, i.e., a higher atomic hydrogen concentration is required for $\mu \mathrm{c}-\mathrm{Si}: \mathrm{H}$ growth. This trend is confirmed by the results obtained from the evaluation of the 
TABLE II. Fraction of atomic hydrogen, silane concentration $\mathrm{SC}_{t}$ at the $\mu \mathrm{c}-\mathrm{Si}: \mathrm{H} / a-\mathrm{Si}: \mathrm{H}$ transition, and ratio $\kappa$ of hydrogen atoms and silane molecules near the filament for $T_{F}=1650$ and $1800{ }^{\circ} \mathrm{C}$.

\begin{tabular}{cccccccc}
\hline \hline & \multicolumn{3}{c}{$T_{F}=1650{ }^{\circ} \mathrm{C}$} & & \multicolumn{3}{c}{$T_{F}=1800{ }^{\circ} \mathrm{C}$} \\
\cline { 2 - 4 } \cline { 6 - 8 }$p_{D}$ & $k_{H}$ & $\mathrm{SC}_{t}$ & $\kappa$ & & $k_{H}$ & $\mathrm{SC}_{t}$ & $\kappa$ \\
\hline $3 \mathrm{~Pa}$ & 0.16 & $7.5 \%$ & 0.191 & & 0.38 & $10 \%$ & 0.155 \\
$5 \mathrm{~Pa}$ & 0.125 & $6 \%$ & 0.194 & & 0.31 & $7.5 \%$ & 0.143 \\
$10 \mathrm{~Pa}$ & 0.09 & $4.2 \%$ & 0.188 & & 0.23 & $5.5 \%$ & 0.142 \\
$20 \mathrm{~Pa}$ & 0.065 & $2.9 \%$ & 0.180 & & & \\
\hline \hline
\end{tabular}

material prepared at $T_{S}=330{ }^{\circ} \mathrm{C}$ (see Fig. 4). There, $20 \%$ lower $\kappa$ are obtained at the higher $T_{F}$, too.

Based on these results, the reactions in the gas phase do not seem to have a significant influence once on the film crystallinity, although the mean free path decreases at higher pressures and the reaction rates of atomic $\mathrm{H}$ and $\mathrm{Si}$ with silane are high (close to the collision limit) and should lead to more reactions of the produced radicals with the remaining silane. However, the concentration of radicals is comparably small and is approximately given by the ratio of the filament surface area to the chamber surface area, estimated to $0.1 \%$, if the dissociation probability of silane at the hot filament surface is high and the assumption that the radicals vanish at the chamber wall. Thus, the gas phase reactions are either not as important as one would expect from the reactions rates, or the effects of the two main reactions \{abstraction reaction [Eq. (3)] and insertion reaction [Eq. (4)] $\}$ compensate each other.

The smaller $\kappa$ at higher filament temperatures can be qualitatively understood in the framework of the existing models, too. For the higher filament temperature, the deposition rates are higher (see Fig. 12) and more hydrogen atoms are produced per silicon atom. As the rates are higher, the impinging radicals have less time to form a crystalline lattice and more hydrogen is needed, e.g., to chemically anneal the silicon network or to etch the disordered material.

The substrate temperature has a strong influence on $\kappa$, as plotted in Fig. 23. With increasing $T_{S} \kappa$ increases, i.e., for higher substrate temperatures less atomic hydrogen is needed to grow crystalline material. At $T_{S}=185^{\circ} \mathrm{C}$, about six to seven hydrogen atoms have to be produced per silicon atom, while at $T_{S}=450{ }^{\circ} \mathrm{C}$ only about two hydrogen atoms are required in order to obtain crystalline film growth.

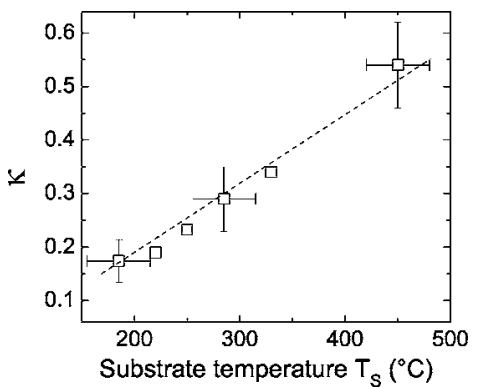

FIG. 23. Ratio $\kappa$ of silane radicals to atomic hydrogen produced at the filament vs the substrate temperature $T_{S}$. The data points have been calculated with Eq. (7) and the experimentally observed silane concentration $S C_{t}$ of the $\mu \mathrm{c}-\mathrm{Si}: \mathrm{H} / a-\mathrm{Si}: \mathrm{H}$ transition.

\section{Deposition rates of microcrystalline silicon}

The best microcrystalline silicon solar cells are prepared near the transition from microcrystalline to amorphous material. Therefore, the SC shift of the $\mu \mathrm{c}-\mathrm{Si}: \mathrm{H} / a-\mathrm{Si}: \mathrm{H}$ transition influences also the deposition rates of $\mu \mathrm{c}-\mathrm{Si}: \mathrm{H}$. High filament temperatures are twofold beneficial for increasing the deposition rate. First, the decomposition of silane is more efficient and second, the transition point is shifted to higher $\mathrm{SC}$ due to the stronger increase of the $\mathrm{H}_{2}$ dissociation. Increasing the deposition pressure has only a small beneficial effect on the deposition rates as SC has to be reduced at higher $p_{D}$ in order to maintain crystalline growth. An increase of the substrate temperature overall results only in a small increase of the deposition rate for $\mu \mathrm{c}-\mathrm{Si}: \mathrm{H}$, because the $\mu \mathrm{c}-\mathrm{Si}: \mathrm{H} / a-\mathrm{Si}: \mathrm{H}$ transition is shifted to higher $\mathrm{SC}$, but $r_{d}$ slightly decreases for increasing $T_{S}$ at fixed SC. However, higher $T_{S}$ relax the constraints for the filament setup, i.e, more filaments, smaller distances or higher $T_{F}$ can be used which all lead to higher $r_{d}$.

\section{Material quality}

An increase of $T_{S}, T_{F}$, or $p_{D}$ leads to an increase of $r_{d}$ for $\mu \mathrm{c}-\mathrm{Si}: \mathrm{H}$, but also affects the material quality. SC and accordingly $I_{C}^{\mathrm{RS}}$ have a systematic influence on most material properties, thus the comparison of the other properties, like the microstructure factor $R$ or optical subgap absorption, is conducted as a function of $I_{C}^{\mathrm{RS}}$. Special attention is paid to material near the $\mu \mathrm{c}-\mathrm{Si}: \mathrm{H} / a-\mathrm{Si}: \mathrm{H}$ transition, where usually the best solar cells are obtained. The hydrogen content increases monotonously with increasing silane concentration for any $T_{S}, T_{F}$, or $p_{D}$. As the plot versus crystallinity in Figs. 7 and 15 shows, $c_{\mathrm{H}}$ increases linearly with amorphous fraction. Simultaneously, the microstructure factor $R$ decreases and often a decrease of the defect density is observed, as evidenced by the spin density or the subgap absorption. The dark and photoconductivities decrease and the photosensitivity increases with increasing amorphous fraction. These observations agree with the existing model of microcrystalline silicon, which is composed of crystallites arranged in columns, surrounded by an amorphous matrix. ${ }^{67-69}$ The bonded hydrogen and the electronic defects are located on the surface of the columns or inside the amorphous matrix, while the crystalline grains do not contain hydrogen. The tissue of high quality $a$-Si:H around the crystalline grains thus leads to a good passivation of the crystalline surfaces, a low defect density and a compact material structure. In highly crystalline material prepared at low SC, on the other hand, the 
amorphous tissue might be etched away (or chemically annealed to crystalline material) by the atomic hydrogen. Then the grain boundaries are formed by hydrogen-passivated crystalline silicon surfaces, as indicated, e.g., by the fine structure of the $2100-\mathrm{cm}^{-1}$ IR-absorption mode. Such material exhibits a high porosity, evidenced by the in-diffusion of atmospheric gases and the oxidation of the material.

A similar effect could have an elevated substrate temperature, which favors the etching of amorphous material and additionally reduces the hydrogen coverage of the growing film surface and of the film. This results in a lower hydrogen content, a higher microstructure factor $R$, and a higher density of dangling bonds. The high $R$ even at low $I_{C}^{\mathrm{RS}}$ might be interpreted by a spatial separation of amorphous and crystalline regions, leading to a porous material structure despite the presence of amorphous material.

In contrast to the previous effects, the increase of $p_{D}$ has only little influence on the hydrogen content, but the intensity of the absorption mode at $850 \mathrm{~cm}^{-1}$ and the microstructure factor increase drastically, even for purely amorphous material. The absorption mode at $850 \mathrm{~cm}^{-1}$ originates from $\left(\mathrm{SiH}_{2}\right)_{n}$ groups in amorphous silicon, thus the increase of $R$ at high pressures originates from a deterioration of the amorphous tissue around the crystalline grains.

Reactions of the film precursors in the gas phase might be a possible reason for the material deterioration at higher $p_{D}$. In the previous section it was argued that the gas-phase reaction do not have an influence on the crystallinity of the film. Nevertheless, they can play an important role for the defect density. This is illustrated by considering the number of atoms involved. Typical defect densities in high quality $\mu \mathrm{c}-\mathrm{Si}: \mathrm{H}$ are about $10^{16} \mathrm{~cm}^{-3}$, i.e., 1 in every $5 \times 10^{6}$ atoms forms a defect state. For the crystallinity, however, nearly all atoms are involved. Thus, if one in a million film precursors (e.g., polysilanes) ends up in a defect, this will have a strong effect on the defect density, but probably not affect the crystallinity. Thus, already a small number of gas-phase reactions can be important for the defect creation.

The insertion and abstraction reaction [Eqs. (3) and (4)] producing $\mathrm{Si}_{2} \mathrm{H}_{4}$ and $\mathrm{SiH}_{3}$ are the starting point in the reaction chain to higher silanes. According to the reported reaction rates, ${ }^{70}$ the probability for these reaction is close to unity. The mean free path for a radical-silane reaction $(\mathrm{H}$ or $\mathrm{Si}$ with $\mathrm{SiH}_{4}$ ) is smaller than the chamber dimensions-at 3 $\mathrm{Pa}, 5 \%$ silane, and a gas temperature of $500 \mathrm{~K}$, the mean free path for a $\mathrm{H}-\mathrm{SiH}_{4}$ collision is about $4 \mathrm{~cm}$-thus most radicals produced at the filament will react with a silane molecule. These primary reaction products are considered to be favorable for a high film quality because they have a high mobility on hydrogen passivated silicon surfaces.

The reaction rate constants of the subsequent reactions are also high, ${ }^{70}$ but as radical-radical reactions are involved, much less reactions occur because the reaction rate is also proportional to the radical densities $n_{i}$ :

$$
\frac{d n_{i}}{d t}=K \cdot n_{i} \cdot n_{j}
$$

As the radical density is much lower than the density of silane molecules, the mean free path for these reaction ex-

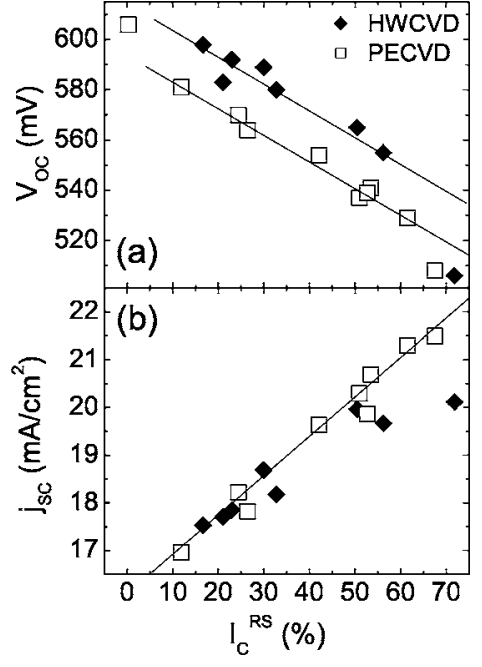

FIG. 24. (a) Open circuit voltages and (b) short circuit current densities of $p-i-n$ solar cells as a function of the Raman intensity ratio $I_{C}^{\mathrm{RS}}$ with $i$ layers prepared by HWCVD and PECVD.

ceeds the chamber dimensions by at least two orders of magnitude, i.e., much less than $1 \%$ of the film precursors will originate from a radical-radical reaction. At higher pressures, the subsequent reactions of the "good" radicals become more important. $\mathrm{SiH}_{2}$ produced by further hydrogen abstraction from $\mathrm{SiH}_{3}$ or higher silanes by the insertion of $\mathrm{SiH}_{2}$ or $\mathrm{Si}$ into $\mathrm{Si}_{2} \mathrm{H}_{4}$ (Ref. 25) lead to a deterioration of the film quality, as evidenced from the microstructure factor or $\mathrm{SiH}_{2}$ scissor modes. ${ }^{28}$ This presence of the less mobile $\mathrm{SiH}_{2}$ radicals and higher silanes could also account for the slightly lower $I_{C}^{\mathrm{RS}}$ of the film with the highest crystallinity at $p_{D}=20 \mathrm{~Pa}$ (see, e.g., Fig. 13).

\section{E. Solar cells}

Using low substrate temperatures and deposition pressures, $\mu \mathrm{c}-\mathrm{Si}: \mathrm{H}$ solar cells with high efficiencies can be prepared. The initial efficiencies of $9.4 \%$ achieved with $i$ layers prepared by HWCVD are equal to the efficiencies obtained with solar cells prepared entirely by PECVD. These solar cells exhibit high fill factors and astonishingly high $V_{\mathrm{oc}}$ (compare Fig. 19), up to $50 \mathrm{mV}$ higher than in comparable solar cells prepared entirely by PECVD with similar efficiencies. $^{20,71,72}$ The solar cell parameters behave very similar upon a variation of SC as previously observed in solar cells prepared by PECVD (compare Fig. 18 and Fig. 6 in Ref. 8).

Figure 24 shows the direct comparison of $J-V$ parameters for solar cells prepared by HWCVD and PECVD as a function of the $i$-layer crystallinity $I_{C}^{\mathrm{RS}}$. The variation of $I_{C}^{\mathrm{RS}}$ values was achieved by adjusting the SC at the $i$-layer deposition. $V_{\mathrm{oc}}$ increases almost linearly with $I_{C}^{\mathrm{RS}}$ for both types of solar cells. The open circuit voltages of the solar cells with $i$ layers prepared by HWCVD are generally about $20 \mathrm{mV}$ higher as those of PECVD solar cells with the same $I_{C}^{\mathrm{RS}}$. However, the highest efficiencies for HWCVD and PECVD solar cells are obtained at different crystallinities (approximately $40 \%$ for $\mathrm{HW}$ and $60 \%$ for PECVD), thus the difference in $V_{\text {oc }}$ for the best devices is about $50 \mathrm{mV} .^{73}$ In the 
region of the highest solar cell efficiencies with $I_{C}^{\mathrm{RS}}$ between $20 \%$ and $60 \%$, the short circuit current densities are similar for both types of solar cells. The difference of $j_{\mathrm{sc}}$ at high $I_{C}^{\mathrm{RS}}$ is due to a slightly smaller $i$-layer thickness and to recombination losses for the highest crystallinity. Similar dark saturation current densities are observed for both types of solar cells, indicating similar defect densities of the $i$-layer material. ${ }^{74}$ On the other hand, lower diode quality factors of the PECVD solar cells point to an enhanced recombination at the interfaces or in the doped layers as possible origin of the lower $V_{\text {oc }}{ }^{73,74}$ which may originate from defects created by ion bombardment, inherent in the PECVD process.

The thickness dependence of the $J-V$ parameters (Fig. 19) also shows the same trends as observed before in PECVD solar cells. ${ }^{72,73} j_{\mathrm{sc}}$ increases with increasing $i$-layer thickness as a result of the increasing absorption in the long wavelength region. The fill factor and $V_{\text {oc }}$ decrease with increasing $i$-layer thickness, caused by the increasing recombination in the bulk and the resulting larger $j_{0}$. The $j_{0}$ of the HW cells are about five times lower than in solar cells of corresponding thickness prepared by PECVD, ${ }^{22}$ thus explaining the $50 \mathrm{mV}$ increase of $V_{\text {oc }}$. The thickness dependence of the $J-V$ characteristics in the dark and under illumination indicates a correlation with the quality of the $i$-layer material. The correlation between $V_{\mathrm{oc}}, j_{0}$ and the material properties, e.g., defect density or effective band gap, is expected by the diode theory, ${ }^{75}$ where $V_{\text {oc }}$ is given by

$$
V_{\mathrm{oc}}=\frac{n k T}{e} \ln \left(\frac{j_{\mathrm{sc}}}{j_{0}}+1\right),
$$

where $n$ is the diode ideality factor, $k_{B}$ the Boltzmann's constant, $T$ the temperature, $e$ the electron charge, and $j_{0}$ the dark saturation current density. In the case of dominant recombination in the bulk of the $i$ layer which is indicated by $n \approx 2, j_{0}$ is given by

$$
j_{0} \propto \frac{n_{i}}{\tau} \propto N_{t} \cdot n_{i}
$$

with $\tau$ the minority carrier lifetime, $N_{t}$ the defect density, and $n_{i}$ the intrinsic charge carrier density. $n$ close to 1 on the other hand, indicates dominant recombination near the interfaces. However, the validity of the superposition principle for the dark current density and the photocurrent density has not been proven yet for microcrystalline silicon solar cells. Strong evidence that this concept can indeed be applied to $\mu \mathrm{c}-\mathrm{Si}: \mathrm{H}$ solar cells is obtained from the experimental data, e.g., by the correlation between $V_{\text {oc }}$ and $j_{0}$ shown in Fig. 21 . The relationship between open circuit voltage and the dark $J-V$ parameters is given by Eq. (9). The data points, which show considerable scatter in Fig. 21, are replotted in Fig. 25 according to Eq. (9). The good agreement with Eq. (9) is evident. The fit to these data points gives a value for $k_{B} T / e$ of $25 \mathrm{mV}$, almost identical to the theoretical value. Some of the cells, in particular, those prepared at a high pressure, show significant deviations from the theoretical value. These solar cells exhibit untypically high diode ideality factors $n$, probably caused by space-charge-limited currents and by recombination reduced photocurrents. Thus, the assumptions

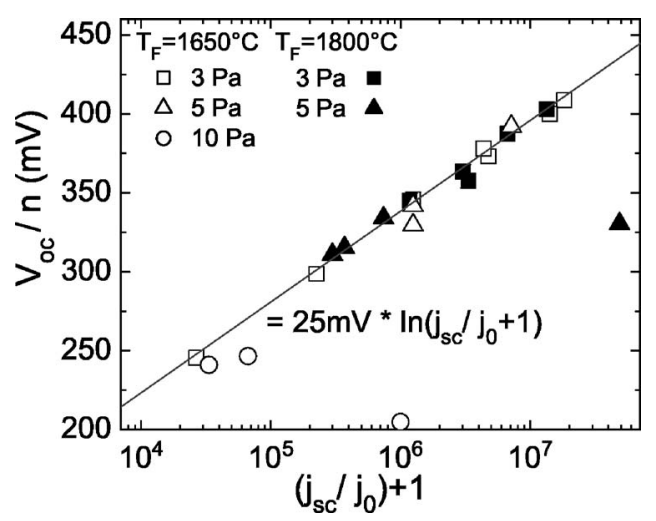

FIG. 25. Open circuit voltage normalized by the diode ideality factor $n$ as a function of the dark saturation current-density $j_{0}$ for the solar cells of Fig. 20 , assuming $j_{\mathrm{sc}}=20 \mathrm{~mA} / \mathrm{cm}^{2}$. The line gives the fit to Eq. (9).

for Eq. (9) are not valid for these pathological cells.

As shown by Fig. 25, the open circuit voltage is fully determined by $j_{0}$. For this reason it is now possible to ascribe $V_{\mathrm{oc}}$ to the material properties $N_{t}$ and $n_{i}$ via Eq. (10). The increase of $V_{\text {oc }}$ by $100 \mathrm{mV}$ (see Fig. 21) is caused by a decrease of $j_{0}$ by approximately two orders of magnitude. According to Eq. (10), $N_{t} \cdot n_{i}$ must then also decrease by two orders of magnitude. However, the defect density measured by ESR or PDS does not show such a strong decrease for increasing SC. The intrinsic carrier density $n_{i}$, on the other hand, is expected to decrease as the amorphous fraction increases because $n_{i}$ of $a-\mathrm{Si}: \mathrm{H}$ is $10^{4}$ times smaller than in $\mu \mathrm{c}-\mathrm{Si}: \mathrm{H}$. The crystalline fraction of $\mu \mathrm{c}-\mathrm{Si}: \mathrm{H}$ solar cells prepared near the transition to amorphous growth is still at least $30 \%$, according to the Raman spectra or the quantum efficiency in the long wavelength region. Thus, the decreasing crystalline fraction with increasing SC can only account for a decrease of $j_{0}$ by a factor of 3 , at most. Furthermore, a shift of the optical band gap is not observed in this material. So the microscopic reason for the decrease of $n_{i}$ remains to be resolved.

The influence of the defect density can be nicely demonstrated by the solar cells and material prepared with different deposition pressure. The highest $V_{\mathrm{oc}}$, and thus also the efficiency, which could be achieved in a SC series near the $\mu \mathrm{c}-\mathrm{Si}: \mathrm{H} / a$-Si:H transition decreases with increasing deposition pressure (Fig. 20) as a result of the increasing $j_{0}$ (Fig. 21). Again, an increase of $n_{i}$ or $N_{t}$ could cause this increase of $j_{0}$. But as shown in Fig. 22, $V_{\text {oc }}$ decreases with increasing $p_{D}$ for a fixed crystalline fraction determined by $I_{C}^{\mathrm{RS}}$. For a fixed composition of amorphous and crystalline phase, however, there is no reason why $n_{i}$ should change. Consequently, the decrease of $V_{\text {oc }}$ must originate from an increase of the defect density. In fact, the material properties clearly indicate a deterioration of the material quality with increasing deposition pressure. The optical absorption in the subgap region increases by one order of magnitude for an increase of $p_{D}$ from 3 to $20 \mathrm{~Pa}$. This increase of the optical absorption can be interpreted as an increase of the defect density $N_{t}$, causing the decrease of $V_{\mathrm{oc}}$. This demonstrates that the open circuit voltage is a sensitive indicator for the material quality if the structural composition is taken into account. 
By decreasing $T_{S}$, a further increase of the achievable $V_{\mathrm{oc}}$ is observed, indicating an improvement of the material quality. A change of $T_{F}$, on the other hand, does not lead to a significant change of $V_{\text {oc }}$ if low deposition pressures are used. Increasing $p_{D}$, however, leads to a faster and more severe deterioration of the solar cell performance in case of $T_{F}=1800^{\circ} \mathrm{C}$. These results show that low $T_{S}$ and $p_{D}$ are essential in order to obtain $\mu \mathrm{c}-\mathrm{Si}: \mathrm{H}$ solar cells with high efficiencies.

\section{CONCLUSION}

$\mu c-S i: H$ prepared by the hot-wire CVD shows excellent material properties and performance in solar cells if low substrate temperatures and deposition pressures are used $\left(T_{S}\right.$ $\left.<285^{\circ} \mathrm{C}, p_{D} \leqslant 5 \mathrm{~Pa}\right)$. At $T_{S}=185^{\circ} \mathrm{C}, \mu \mathrm{c}-\mathrm{Si}: \mathrm{H}$ solar cells with efficiencies $(\eta=9.4 \%)$ similar to those obtained by PECVD can be prepared.

The influence of various deposition parameters $-\mathrm{SC}, p_{D}$, $T_{S}$, and $T_{F}$ - on the deposition rate, crystallinity, and microstructure, as well as electronic defects and conductivity, was investigated and led to a better understanding of the deposition process. The deposition rates for $\mu \mathrm{c}-\mathrm{Si}: \mathrm{H}$ material could be explained by the arrival rate of silane molecules on the filament and the temperature dependence of the silane dissociation at the filament. The $\mu \mathrm{c}-\mathrm{Si}: \mathrm{H} / a-\mathrm{Si}: \mathrm{H}$ transition was found to be determined by the flux of atomic hydrogen produced at the flilament. Consequently, the deposition rates for $\mu \mathrm{c}-\mathrm{Si}: \mathrm{H}$ are limited by the thermal radiation of the filaments if low substrate temperatures are desired. Hydrogen desorption during the film deposition leads to a deterioration of the material quality at higher $T_{S}$, i.e., high defect densities and a porous material structure are observed. Besides the low $T_{S}$, also low deposition pressures are favorable to obtain material of high quality. Secondary radical-radical reactions are proposed as the origin for the deterioration of the material quality at higher $p_{D}$.

Independent of the deposition conditions and deposition method-HW or PECVD - the best material properties are found at the onset of amorphous material growth, controlled by adjusting the silane concentration. At low SC material with high crystallinity but also high defect density and porosity is obtained, while at high SC compact material with considerable amorphous fractions, leading to excellent grain boundary passivation, is obtained. Solar cells show an increasing $V_{\text {oc }}$ with increasing SC and a maximum of the fill factor and the efficiency at the onset of amorphous growth. The same behavior has previously been observed for solar cells prepared entirely by PECVD, but the $V_{\text {oc }}$ observed for the HWCVD solar cells are considerably higher (up to 600 $\mathrm{mV}$ ) and linked to higher amorphous volume fractions homogeneously distributed in the $i$ layers. This could only be achieved by HWCVD so far.

\section{ACKNOWLEDGMENTS}

The authors gratefully acknowledge the help of J. Wolff, M. Hülsbeck, L. Baia Neto, T. Dylla, H. Siekmann, G. Schöpe, and the financial support of BMBA under Contract No. 0329814A.
${ }^{1}$ W. Hoffmann, in Proceedings of the 17th EPVSEC, Munich, Germany, 2001, edited by B. McNellis, W. Palz, A. Ossenbrink, and P. Helm (WIPMunich, München, Germany, 2002), p. 851.

${ }^{2}$ B. Rech and H. Wagner, Appl. Phys. A: Mater. Sci. Process. 69, 155 (1999).

${ }^{3}$ L. Guo, M. Kondo, M. Fukawa, K. Saitoh, and A. Matsuda, Jpn. J. Appl. Phys., Part 2 37, L1116 (1998).

${ }^{4}$ J. Meier et al., Mater. Res. Soc. Symp. Proc. 420, 3 (1996).

${ }^{5}$ K. Saito, M. Sano, K. Matuda, T. Kondo, T. Nishimoto, K. Ogawa, and I. Kajita, in Proceedings of the Second World Conference on Photovoltaic Solar Energy Conversion, Vienna, Italy, 1998 (European Commission, Ispra, Italy, 1998), p. 351

${ }^{6}$ K. Yamamoto, M. Yoshimi, Y. Tawada, Y. Okamoto, A. Nakajima, and S. Igari, Appl. Phys. A: Mater. Sci. Process. 69, 179 (1999).

${ }^{7}$ T. Repmann, W. Appenzeller, T. Roschek, B. Rech, and H. Wagner, Proceedings of the 28th Photovoltaic Specialists Conference, Anchorage, USA, 2001 (IEEE, Piscataway, NJ, 2001), p. 912.

${ }^{8}$ O. Vetterl et al., Sol. Energy Mater. Sol. Cells 62, 97 (2000).

${ }^{9}$ A. H. Mahan, J. Carapella, B. P. Nelson, R. S. Crandall, and I. Balberg, J. Appl. Phys. 69, 6728 (1991).

${ }^{10}$ H. Matsumura, Jpn. J. Appl. Phys., Part 1 37, 3175 (1998).

${ }^{11}$ J. K. Rath, Sol. Energy Mater. Sol. Cells 76, 431 (2003).

${ }^{12}$ J. Cifre, J. Bertomeu, J. Puigdollers, M. Polo, J. Andreu, and A. Lloret, Appl. Phys. A: Solids Surf. A59, 645 (1994).

${ }^{13}$ R. E. I. Schropp, Y. Xu, E. Iwaniczko, G. A. Zaharias, and A. H. Mahan, Appl. Phys. A: Mater. Sci. Process. 715, A26.3 (2002).

${ }^{14}$ K. Ishibashi, M. Karasawa, G. Xu, N. Yokokawa, M. Ikemoto, A. Masuda, and H. Matsumura, Thin Solid Films 430, 58 (2003).

${ }^{15}$ A. Ledermann, U. Weber, C. Mukherjee, and B. Schröeder, Thin Solid Films 395, 61 (2001).

${ }^{16}$ R. E. I. Schropp, Thin Solid Films 395, 17 (2001).

${ }^{17}$ S. Klein, F. Finger, R. Carius, H. Wagner, and M. Stutzmann, Thin Solid Films 395, 305 (2001).

${ }^{18}$ A. L. Baia Neto, A. Lambertz, R. Carius, and F. Finger, Phys. Status Solidi A 186, R4 (2001).

${ }^{19}$ O. Vetterl, A. Dasgupta, A. Lambertz, H. Stiebig, F. Finger, and H. Wagner, Mater. Res. Soc. Symp. Proc. 664, A25.8 (2001).

${ }^{20}$ T. Roschek, T. Repmann, J. Muller, B. Rech, and H. Wagner, J. Vac. Sci. Technol. A 20, 492 (2002).

${ }^{21}$ S. Klein, J. Wolff, F. Finger, R. Carius, H. Wagner, and M. Stutzmann, Jpn. J. Appl. Phys., Part 2 42, L11 (2002).

${ }^{22}$ S. Klein, F. Finger, R. Carius, B. Rech, M. Luysberg, and M. Stutzmann, Mater. Res. Soc. Symp. Proc. 715, A26.2 (2002).

${ }^{23}$ H. L. Duan, G. A. Zaharias, and S. F. Bent, Mater. Res. Soc. Symp. Proc. 715, A15.1 (2002).

${ }^{24}$ M. Heintze, R. Zedlitz, H. N. Wanka, and M. B. Schubert, J. Appl. Phys. 79, 2699 (1996).

${ }^{25}$ S. Tange, K. Inoue, K. Tonokura, and M. Koshi, Thin Solid Films 395, 42 (2001).

${ }^{26}$ H. Umemoto, K. Ohara, D. Morita, Y. Nozaki, A. Masuda, and H. Matsumura, J. Appl. Phys. 91, 1650 (2002).

${ }^{27}$ A. Gallagher, Thin Solid Films 395, 25 (2001).

${ }^{28}$ E. Molenbroek, A. Mahan, and A. Gallagher, J. Appl. Phys. 82, 1909 (1997).

${ }^{29}$ Y. Nozaki, M. Kitazoe, K. Horii, H. Umemoto, A. Masuda, and H. Matsumura, Thin Solid Films 395, 47 (2001).

${ }^{30}$ P. Ho, W. Breiland, and R. Buss, J. Chem. Phys. 91, 2627 (1989).

${ }^{31}$ R. Doyle, R. Robertson, G. Lin, M. He, and A. Gallagher, J. Appl. Phys. 64, 3215 (1988).

${ }^{32}$ J. Perrin, J. Non-Cryst. Solids 137-138, 639 (1991).

${ }^{33}$ H. Matsumura, J. Appl. Phys. 65, 4396 (1989).

${ }^{34}$ S. Veprek and M. G. J. Veprek-Heijman, Appl. Phys. Lett. 56, 1766 (1990).

${ }^{35}$ W. Futako, K. Yoshino, C. M. Fortmann, and I. Shimizu, J. Appl. Phys. 85, 812 (1999).

${ }^{36}$ K. Nakamura, K. Yoshino, S. Takeoka, and I. Shimizu, Jpn. J. Appl. Phys., Part 1 34, 442 (1995).

${ }^{37}$ H. Shirai, D. Das, J. Hanna, and I. Shimizu, Appl. Phys. Lett. 59, 1096 (1991).

${ }^{38}$ M. Fang, J. Chevrier, and B. Drevillon, J. Non-Cryst. Solids 137-138, 791 (1991).

${ }^{39}$ M. Heintze, W. Westlake, and P. Santos, J. Non-Cryst. Solids 164-166, 985 (1993)

${ }^{40}$ S. Vepřek and V. Mareček, Solid-State Electron. 11, 683 (1968). 
${ }^{41}$ A. Matsuda, J. Non-Cryst. Solids 59-60, 767 (1983).

${ }^{42}$ A. Matsuda, Thin Solid Films 337, 1 (1999).

${ }^{43}$ W. Beyer and M. S. Abo Ghazala, Mater. Res. Soc. Symp. Proc. 507, 601 (1998).

${ }^{44}$ C. Fang, K. Gruntz, L. Ley, M. Cardona, F. Demond, G. Muller, and S. Kalbitzer, J. Non-Cryst. Solids 35-36, 255 (1980).

${ }^{45}$ J. Müller, F. Finger, R. Carius, and H. Wagner, Phys. Rev. B 60, 11666 (1999).

${ }^{46}$ O. Kluth, O. Vetterl, R. Carius, F. Finger, S. Wieder, B. Rech, and H. Wagner, Mater. Res. Soc. Symp. Proc. 557, 731 (1999).

${ }^{47}$ J. Lossen, S. Klein, and F. Finger, Thin Solid Films 451-452, 531 (2004).

${ }^{48}$ Q. Zhang, M. Zhu, L. Wang, and F. Liu, Thin Solid Films 430, 50 (2003).

${ }^{49}$ Y. Chabal, Phys. Rev. Lett. 50, 1850 (1983).

${ }^{50}$ U. Kroll, J. Meier, A. Shah, S. Mikhailov, and J. Weber, J. Appl. Phys. 80, 4971 (1996).

${ }^{51}$ S. Agarwal, A. Takano, M. C. M. van de Sandenm, D. Maroudas, and E. S. Aydil, J. Chem. Phys. 117, 10805 (2002).

${ }^{52}$ A. H. Mahan, L. M. Gedvilas, and J. D. Webb, J. Appl. Phys. 87, 1650 (2000).

${ }^{53}$ T. Dylla, F. Finger, and R. Carius, Mater. Res. Soc. Symp. Proc. 762, A2.5 (2003).

${ }^{54}$ A. L. Baia Neto, A. Lambertz, R. Carius, and F. Finger, J. Non-Cryst. Solids 299-302, 274 (2002).

${ }^{55}$ F. Finger, P. Hapke, M. Luysberg, R. Carius, H. Wagner, and M. Scheib, Appl. Phys. Lett. 65, 2588 (1994).

${ }^{56}$ N. Wyrsch, M. Goerlitzer, N. Beck, J. Meier, and A. Shah, Mater. Res. Soc. Symp. Proc. 420, 801 (1996).

${ }^{57}$ R. Brüggemann, A. Hierzenberger, P. Reinig, M. B. Schubert, S. Schweizer, H. N. Wanka, and I. Zrinščak, J. Non-Cryst. Solids 227-230, 982 (1998).

${ }^{58}$ U. Backhausen, R. Carius, F. Finger, P. Hapke, U. Zastrow, and H. Wagner, Mater. Res. Soc. Symp. Proc. 452, 833 (1997).

${ }^{59} \mathrm{H}$. Overhof and M. Otte, in Future Directions in Thin Film Science and
Technology, edited by J. M. Marshall, N. Kirov, A. Vavrek, and J. M. Maud (World Scientific, Singapore, 1997), p. 23.

${ }^{60}$ K. F. Feenstra, R. E. I. Schropp, and W. F. van der Weg, J. Appl. Phys. 85, 6843 (1999).

${ }^{61}$ D. L. Staebler and C. R. Wronski, Appl. Phys. Lett. 31, L292 (1977).

${ }^{62}$ H. Keppner et al., Sol. Energy Mater. Sol. Cells 34, 201 (1994).

${ }^{63}$ S. Klein, Ph.D. thesis, Technische Universität München (2004).

${ }^{64}$ S. Klein, F. Finger, R. Carius, T. Dylla, B. Rech, M. Grimm, L. Houben, and M. Stutzmann, Thin Solid Films 430, 202 (2003).

${ }^{65}$ K. Tonokura, K. Inoue, and M. Koshi, J. Non-Cryst. Solids 299-302, 25 (2002).

${ }^{66} \mathrm{C}$. S. U. Department of Chemical Engineering, CHEMKIN: Chemical equilibrium calculator provided online by the Department of Chemical Engineering, Colorado State University (http://grashof.engr.colostate.edu/tools/ equil.html).

${ }^{67}$ F. Finger, J. Müller, C. Malten, and H. Wagner, Philos. Mag. B 77, 805 (1998).

${ }^{68}$ L. Houben, M. Luysberg, P. Hapke, R. Carius, F. Finger, and H. Wagner, Philos. Mag. A 77, 1447 (1998).

${ }^{69}$ H. Overhof, J. Non-Cryst. Solids 227-230, 992 (1998)

${ }^{70}$ J. Perrin, O. Leroy, and M. Brodage, Contrib. Plasma Phys. 36, 3 (1996).

${ }^{71}$ J. Meier et al., Sol. Energy Mater. Sol. Cells 66, 73 (2001).

${ }^{72}$ O. Vetterl, A. Lambertz, A. Dasgupta, F. Finger, B. Rech, O. Kluth, and H. Wagner, Sol. Energy Mater. Sol. Cells 66, 345 (2001).

${ }^{73}$ S. Klein, T. Repmann, and T. Brammer, Sol. Energy 77, 893 (2004).

${ }^{74}$ Y. Mai, S. Klein, X. Geng, M. Hülsbeck, R. Carius, and F. Finger, Thin Solid Films (to be published).

${ }^{75}$ S. M. Sze, Physics of Semiconductor Devices, 2nd ed. (Wiley, New York, 1981).

${ }^{76}$ E. Molenbroek, A. Mahan, E. Johnson, and A. Gallagher, J. Appl. Phys. 79, 7278 (1996).

${ }^{77}$ T. Tanaka, M. Hiramatsu, M. Nawata, A. Kono, and T. Goto, J. Phys. D 27, 1660 (1994) 